\title{
Honeywell
}

\section{Installation and Implementation of an In-Process Coordinate Measuring Machine (CMM)}

Federal Manufacturing \& Technologies

Derek Johnston

KCP-613-8524

October 2008

Final Report

Approved for public release; distribution is unlimited.

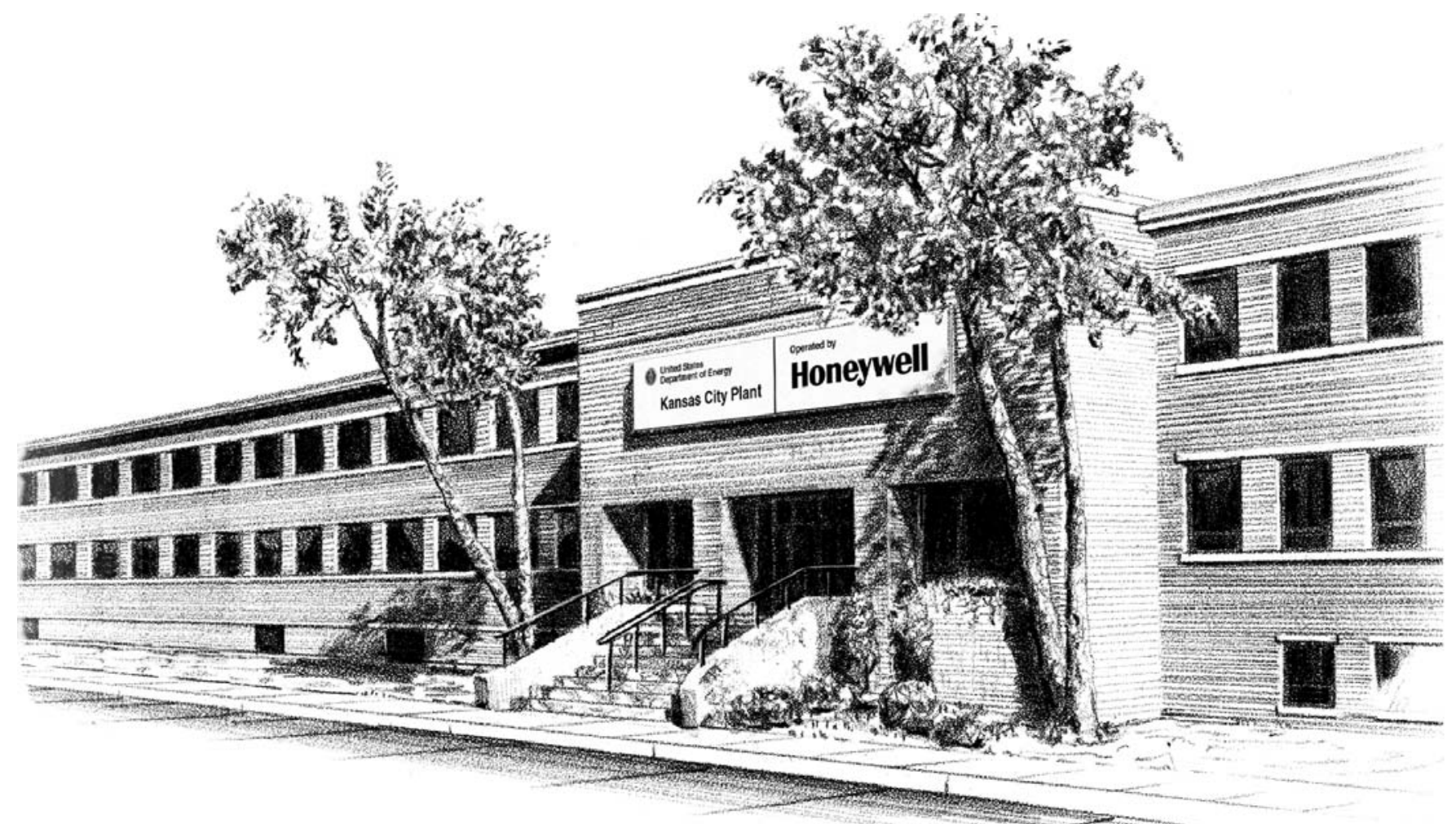

Prepared under prime contract DE-ACO4-01AL66850 for the United States Department of Energy 


\section{DISCLAIMER}

This report was prepared as an account of work sponsored by an agency of the United States Government. Neither the United States Government nor any agency thereof, nor any of their employees, makes any warranty, express or implied, or assumes any legal liability or responsibility for the accuracy, completeness, or usefulness of any information, apparatus, product, or process disclosed, or represents that its use would not infringe privately owned rights. Reference herein to any specific commercial product, process or service by trade names, trademark, manufacturer, or otherwise, does not necessarily constitute or imply its endorsement, recommendation or favoring by the United States Government or any agency thereof. The views and opinions of authors expressed herein do not necessarily state or reflect those of the United States Government or any agency thereof.

All data prepared, analyzed and presented has been developed in a specific context of work and was prepared for internal evaluation and use pursuant to that work authorized under the reference contract. Reference herein to any specific commercial product, process or service by trade name, trademark, manufacturer, or otherwise, does not necessarily constitute or imply its endorsement, recommendation or favoring by the United States Government, any agency thereof or Honeywell Federal Manufacturing \& Technologies, LLC.

Printed in the United States of America.

This report has been reproduced from the best available copy.

Available to DOE and DOE contractors from the Office of Scientific and Technical Information, P.O. Box 62, Oak Ridge, Tennessee 37831; prices available from (865) 576-8401, FTS 626-8401.

Available to the public from the National Technical Information Service, U.S. Department of Commerce, 5285 Port Royal, Rd., Springfield, Virginia 22161, (703) 487-4650.

A prime contractor with the United States Department of Energy under Contract Number DE-AC04-O1AL66850

\author{
Honeywell Federal Manufacturing \& Technologies \\ P.O. Box 419159 \\ Kansas City, Missouri, 64141-6159
}




\section{Honeywell}

KCP-613-8524

Distribution Category UC-42

Approved for public release; distribution is unlimited.

Installation and Implementation of an In-Process Coordinate

Measuring Machine (CMM)

Derek Johnston

October 2008

Final Report

Derek Johnston, Project Leader 



\section{Contents}

Section

Page

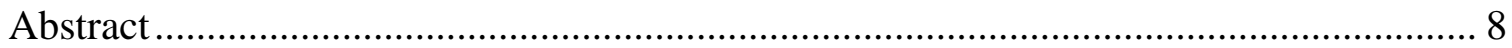

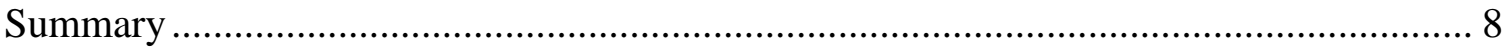

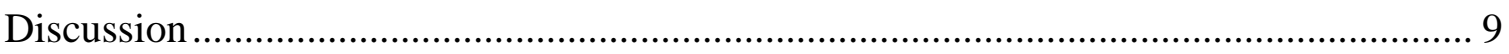

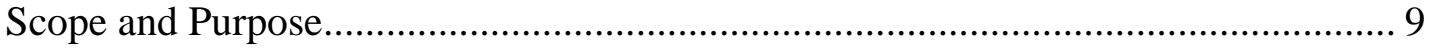

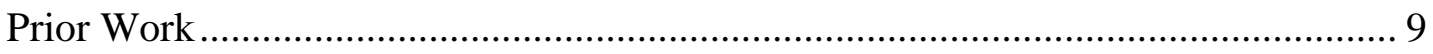

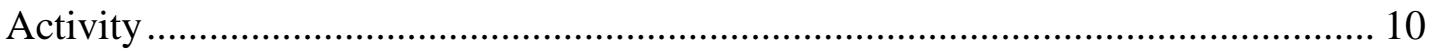

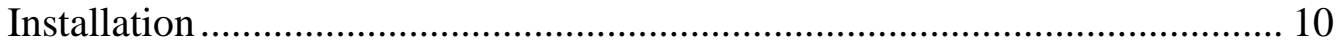

Calibration Procedures .......................................................................... 11

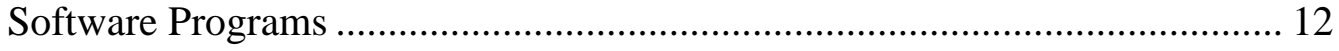

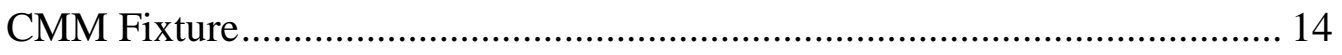

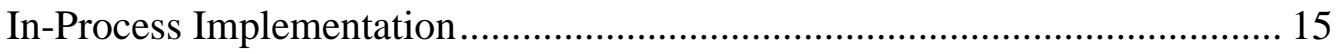

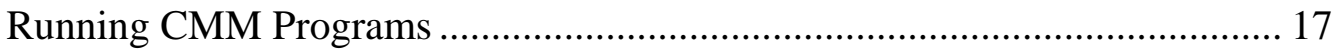

Generating Reports ........................................................................ 21

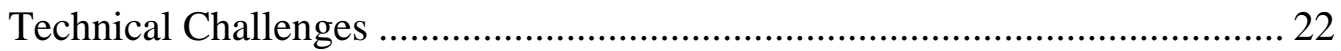

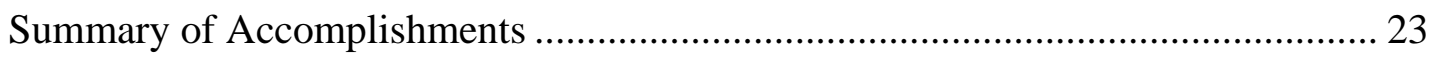

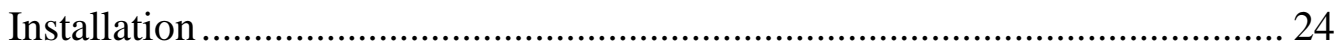

Metrolog and Silma CMM Software Training ........................................... 24

Calibration Procedures ............................................................................... 24

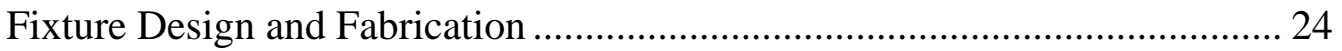

Troubleshooting and Technical Know-How .............................................. 24 
Software License Updates and Upgrades .......................................................... 25

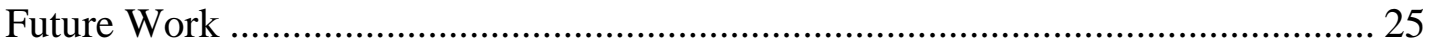

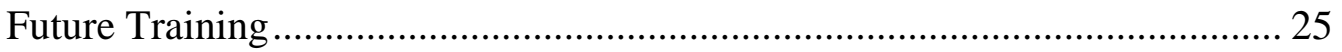

Program Control and Documentation............................................................... 26

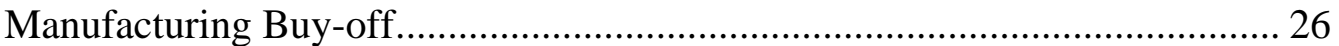

Classified Network .................................................................................... 26

Appendices

A. Programming and Product Definitions ............................................................ 27

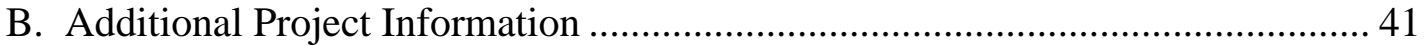




\section{Illustrations}

Figure Page

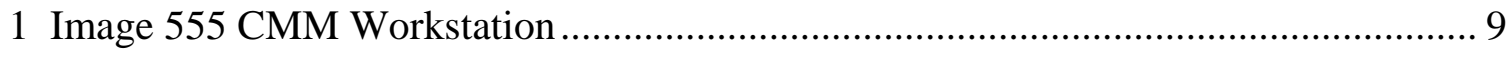

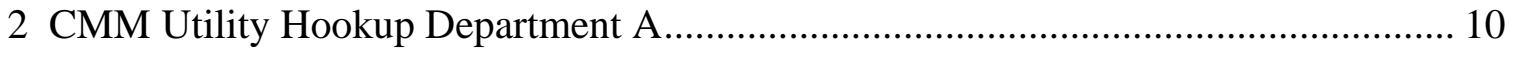

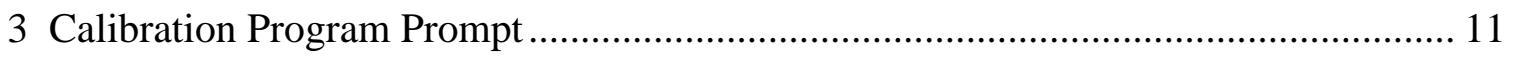

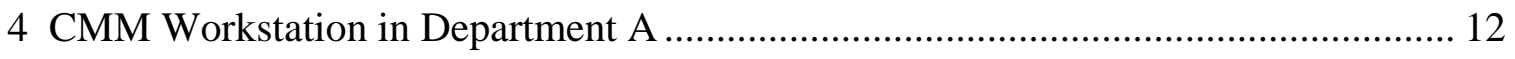

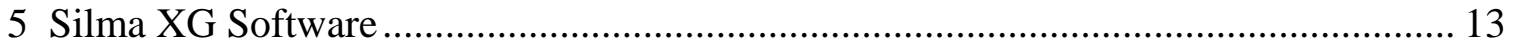

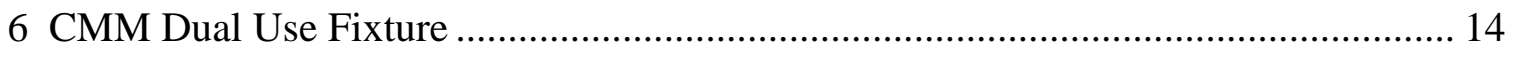

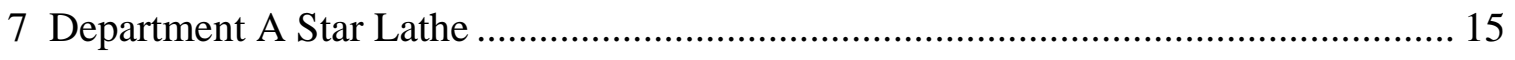

8 Department A Star Tool Holders and Live Tooling ............................................... 16

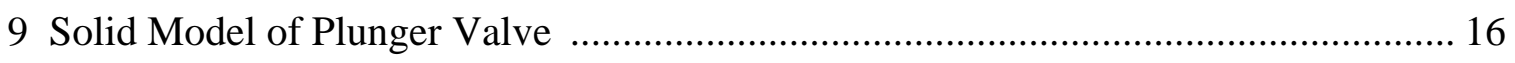

10 Silma XG Simulated Probe Touch Points........................................................... 17

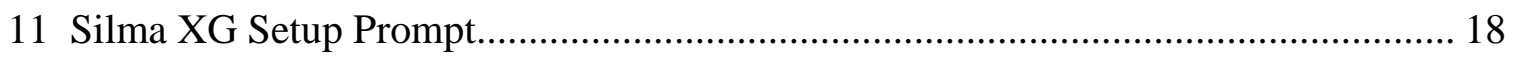

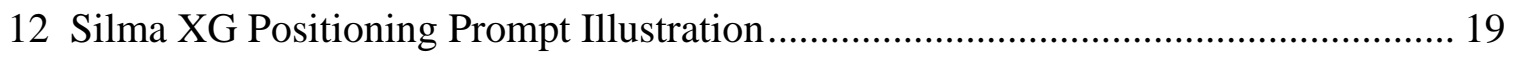

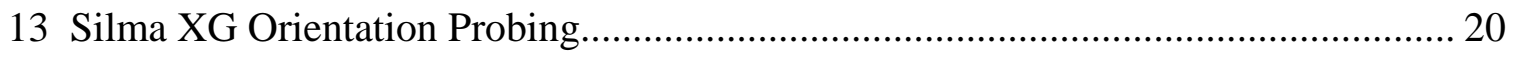

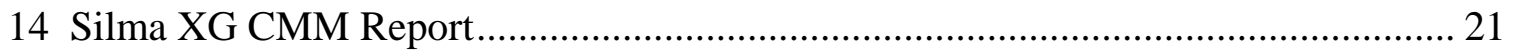




\begin{abstract}
This report documents the work accomplished during the installation and implementation of the in-process Coordinate Measuring Machine (CMM) in Department A. A wealth of knowledge has been gained in solving the many technical issues that delayed the partial implementation of this CMM. The work completed thus far lead to the successfully calibrated in-process CMM workstation. A great deal of current and future work has been outlined in the following pages that shall be used as a guide for the full implementation of this CMM with machining processes in Department A.
\end{abstract}

\title{
Summary
}

This project builds upon the previous work completed in Department B. In that department, engineers had already established an in-process verification tool by utilizing the Image 555 and Image 777 CMM workstations.

In order to reduce costs and increase the utilization of the existing two CMM workstations, the Image 555 was relocated from Department B to Department A. The relocation was relatively simple and straight forward. However, the implementation was a tremendous challenge that consumed more time than expected and yielded fewer results than anticipated. The first technical challenge was isolating the vibrations in the floor generated from adjacent machines. In Department B, the CMM was located on a separate concrete pad that isolated vibrations created by adjacent machines. In Department A, the CMM was placed on the same concrete floor as that of the adjacent turning machines in Department A. In order to isolate the vibrations from the machines a set of isolation dampener pads were utilized. Several different types of dampener pads had to be experimented with in order to reduce the vibrations without jeopardizing the stability of the CMM. The final solution to the vibrations and stability control resulted in a midrange dampener pad that was used with a slower traverse speed set for on the CMM.

In order to make this CMM more user-friendly for both the operator and the engineer, a different type of CMM software system was chosen, Metrolog XG. Metrolog XG, in combination with Silma XG, provides the user with a visual-based programming tool that is easier to understand than typical DMIS coding, as was used in Department B. The Metrolog and Silma software allows the engineers to program off-line in a virtual simulation to test CMM programs before running the real part on the actual CMM.

Several CMM programs were created for calibration purposes using the new software and CMM. Two products were evaluated and used as an example throughout this report, illustrating how the in-process CMM works with the user-friendly software. 


\section{Discussion}

\section{Scope and Purpose}

The intent of this project was to install and implement an operator friendly CMM workstation for in-process verification of products in Department A. The justification for this project was based upon several machined products in the department that require the use of expensive gages, first piece CMM inspection through Precision Measurement, and/or difficult to use comparator charts for work piece verification. The sought after benefits of an in-process CMM were immediate and accurate inspection results that could be utilized by virtually any machinist in the department once a CMM program/process was developed. Figure 1 illustrates the Image 555 CMM installed in Department A.

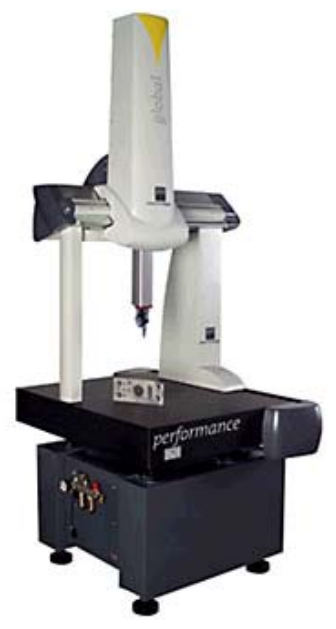

Figure 1: Image 555 CMM Workstation

\section{Prior Work}

This Image 555 CMM was already installed and implemented in Department B, by two engineers. These engineers have successfully developed in-process CMM programs for operators to use on products. Work in Department B continues with the use of a similar CMM workstation called the Image 777. 


\section{Activity}

\section{$\underline{\text { Installation }}$}

Due to the lack of extra floor space in Department A, an existing OGP comparator had to be excessed in order to make room for the new Image $555 \mathrm{CMM}$.

An Industrial Hygienist coordinated the beryllium surface contamination sampling for the Department A's optical comparator. The results indicated no measureable amounts of contamination near or around the proposed CMM work cell prior to installation.

Utility costs, hookup, and transportation were expensed by facilities, as the current comparator was slated for excess and the new CMM was simply being relocated inside KCP. No additional charges to the project were accrued for the entire installation, saving the project roughly $\$ 20 \mathrm{~K}$. Figure 2 shows the final installation of the CMM in Department A.
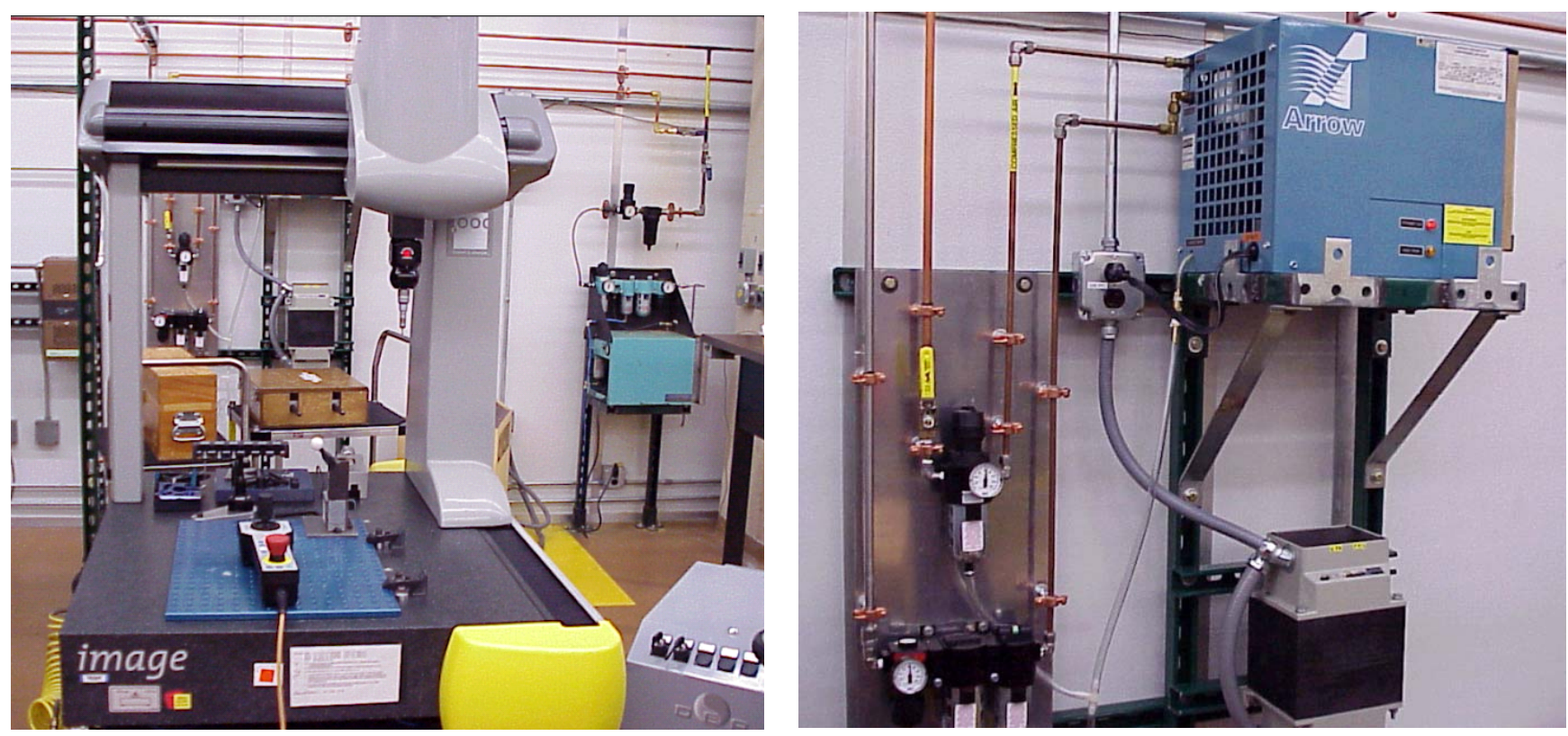

Figure 2: CMM Utility Hookup Department A 


\section{$\underline{\text { Calibration Procedures }}$}

A new calibration procedure was developed through a combined effort by a Numerical Control Analyst, an Electrical Technician, and Metrology Senior Engineer. The previous calibration procedure used for this CMM in Department B could not be used because of the new CMM software, Metrolog XG. The following list discusses the personnel involved in the development of the CMM calibration procedures and the type of work that each contributed.

\section{Numerical Control Analyst}

Developed CMM software programs to check the accuracy and repeatability of the CMM according to the calibration procedure. The analyst developed CMM coding for the probe tip calibration, ball plates, and Z-plates. Figure 3 illustrates an example of the calibration command prompt as seen in the program by the technicians.

\section{Electrical Technician}

The technician was the primary contact for machine maintenance, setting up calibration data storage links, troubleshooting, and aided in developing the proper documentation for the calibration procedures.

\section{Metrology Engineer}

The engineer generated the calibration procedure document. This document is used to call out all of the necessary programs, steps, and equipment required by Metrology to verify the accuracy and repeatability of the CMM throughout the entire useful range of operation.

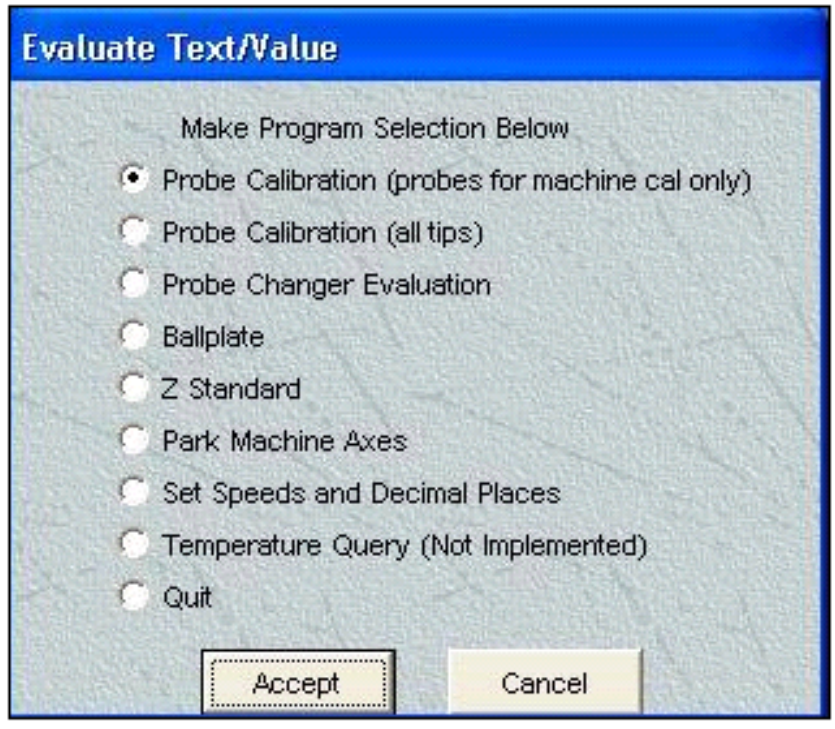

Figure 3: Calibration Program Prompt 


\section{$\underline{\text { Software Programs }}$}

Department B currently uses a software program called PCDMIS which is based primarily on DMIS logic. Engineers write CMM programs for various products that are manufactured in Department B. Once the program is written, the operator is able to run the program in 'operator-only' mode which safeguards some of the functions of the CMM and the program. The operator-only mode is intended to be a more straightforward and simple approach to using the CMM software.

In Department A, a different type of CMM software, Metrolog, was chosen based on an early review of the user-friendly programming architecture. Metrologic Group Inc. has been, and still is, successfully used throughout KCP by several engineers and operators. However, at any one time there are approximately a dozen different CMM program types being used to check a product. Typically, the type of software used, is based on what the CMM machine is capable of running, what the operator knows how to use, or what software was provided with the different CMM machine upon original purchase. Metrologic was chosen because of the visual off-line programming feature as described in the following sections.

\section{On-Line Software}

Metrolog XG is considered the 'on-line' or 'at the CMM' programming tool that engineers and operators can use to write programs and verify parts. The software allows the user to visually see on the computer simulation exactly what the adjacent CMM is performing. This software system also is used during the calibration and verification routines by maintenance and metrology. The Metrolog XG software works with the Brown \& Sharp controller to drive the Global Image 555 CMM to different points based upon operator input or program logic. Figure 4 shows the complete CMM setup in Department A with the PC and controller.

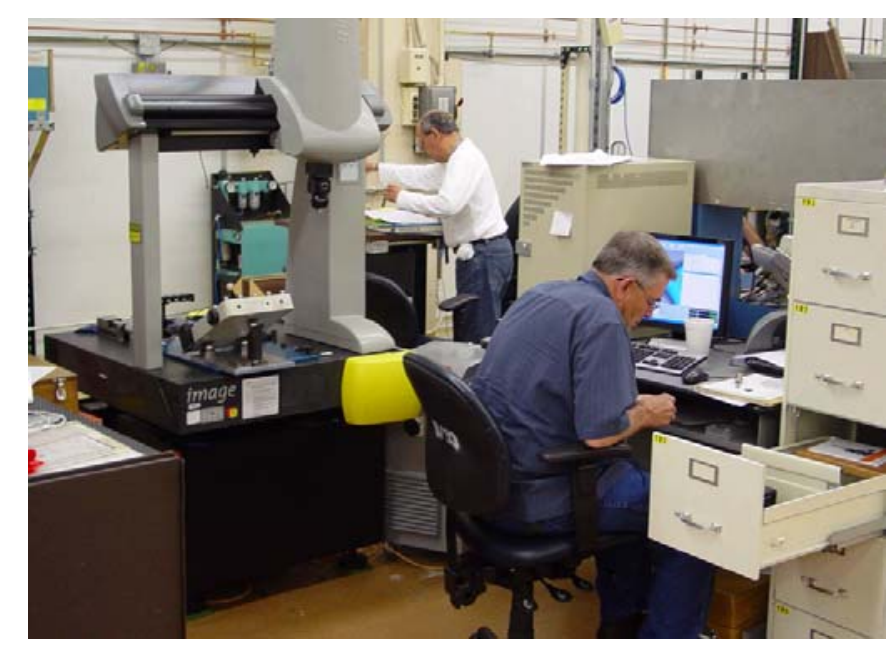

Figure 4: CMM Workstation in Department A 


\section{Off-Line Software}

The off-line software is what makes this particular software package unique and more cost effective for the engineer. The Silma XG software is essentially the virtual duplication of the actual CMM machine in Department A. This software tool allows engineers or programmers to build CMM programs and test their work in virtual reality before running on the actual machine using Metrolog XG. By programming from solid models generated in CAD systems such as SolidWorks or Pro-E, engineers are able to test an inspection process before a final definition has been established, saving designers and manufacturing time and money.

In order to reduce operating costs, a floating license was setup for multiple engineers. The convenience of the Silma software allows engineers to work at their desk in order to quickly pull up additional programs or converse with other engineers in their department. Figure 5 shows the Silma XG software with a modeled representation of the true CMM.

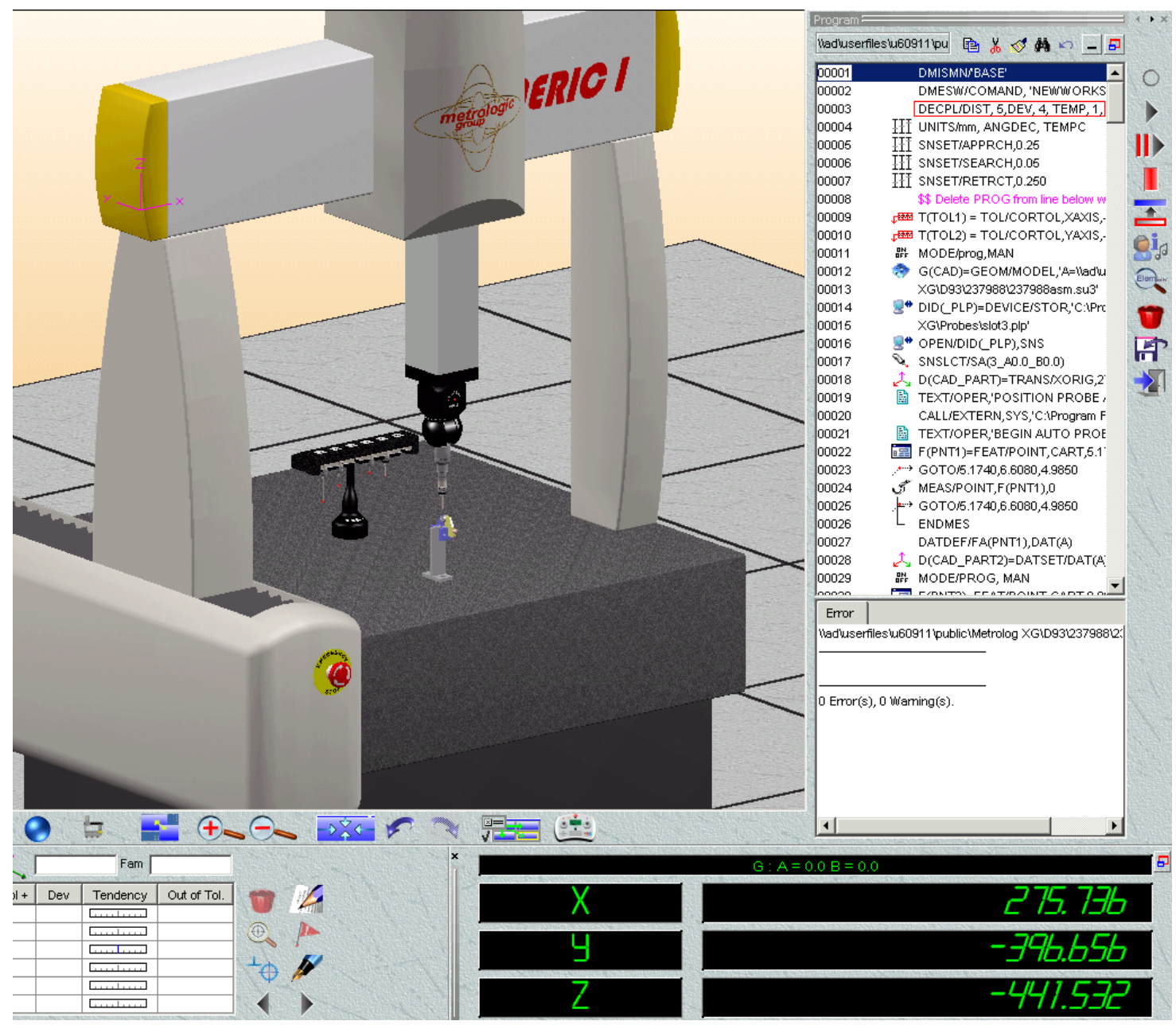

Figure 5: Silma XG Software 


\section{CMM Fixture}

Many traditional fixtures such as V-blocks, standoffs, and Kurt vises are inadequate for smaller parts with multiple features. Therefore, due to the relatively large range of parts and part sizes in Department A, custom fixtures were necessary as shown in Figure 6. The new fixture was designed to allow the CMM to probe all of the necessary features without contacting the fixture or repositioning the part. With a slight modification, the fixture below was adapted for two parts that are part of active programs at KCP and will benefit from the use of an in-process CMM.

Plunger Valve

Piston 2Z Valve
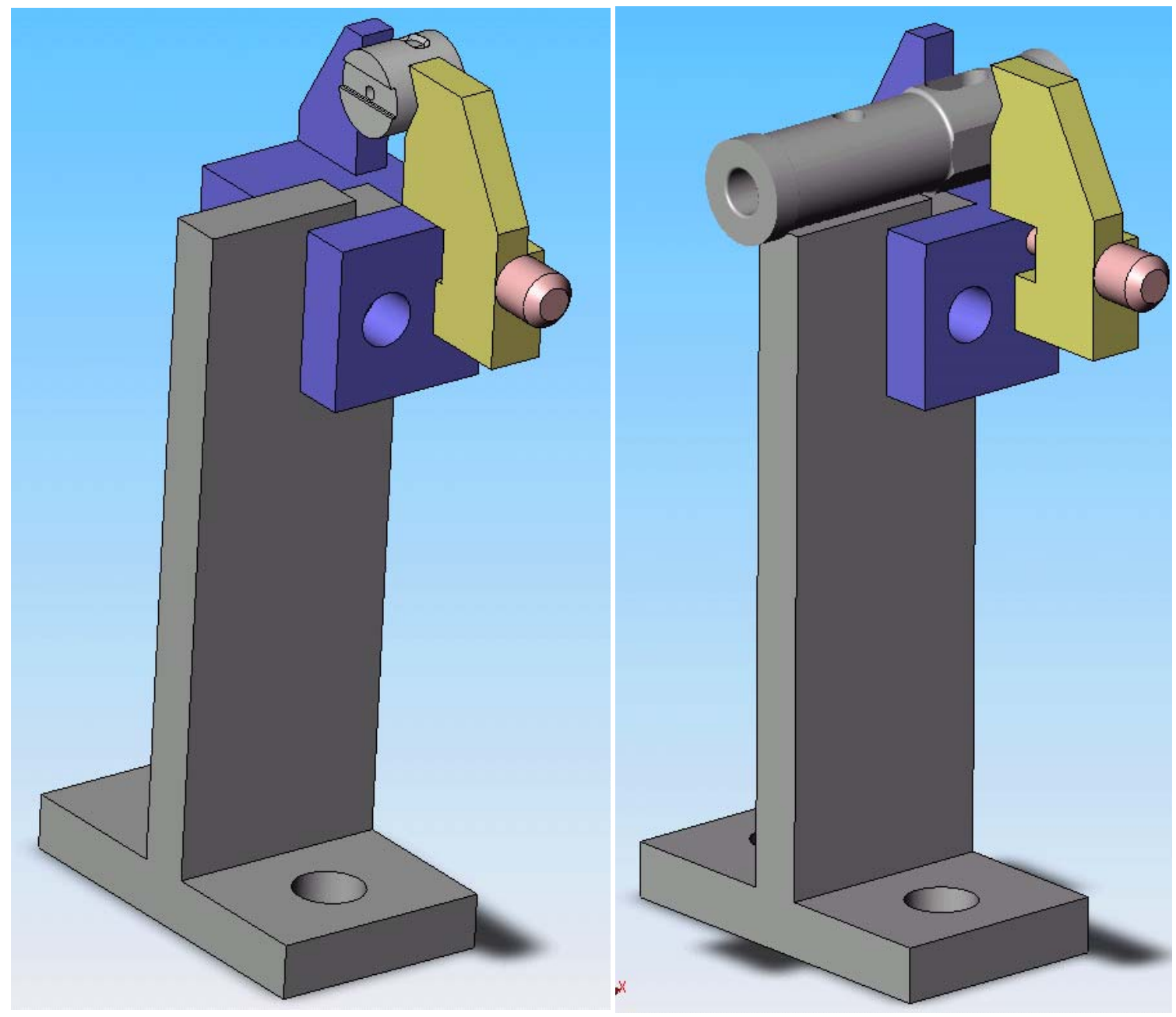

Figure 6: CMM Dual Use Fixture 


\section{$\underline{\text { In-Process Implementation }}$}

The immediate need and further justification for this CMM stems from small parts such as the Plunger Valve and the $2 \mathrm{Z}$ Valve as previously discussed. The complexity of these parts along with the tight tolerance on several of the features requires a highly accurate turning center or lathe such as the Star machine as shown in Figure 7.

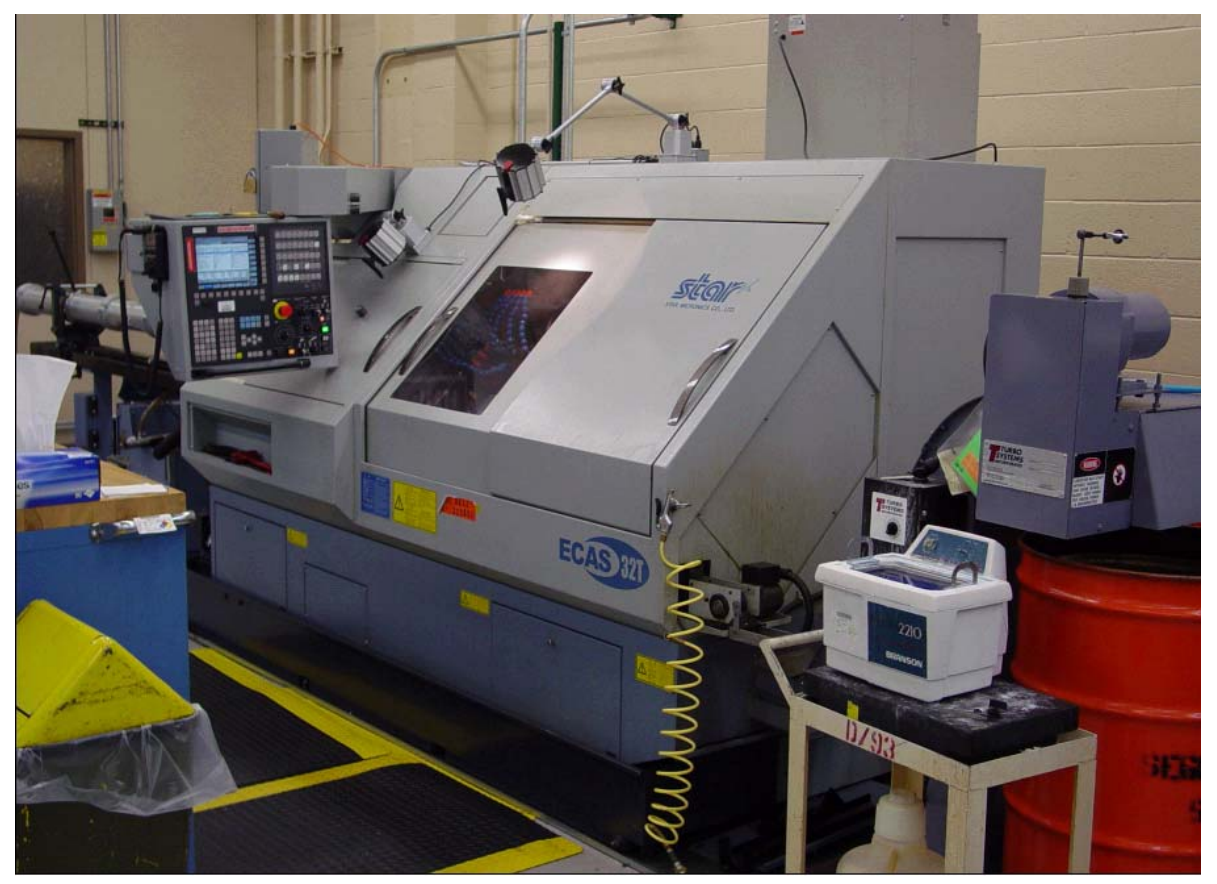

Figure 7: Department A Star Lathe

The tight tolerance of the many features and the relationship between each feature is what can make manufacturing difficult and expensive. In order to hold the tolerance and relationships between multiple features, several turning and live tools must be accurately synchronized with one another within a few tenths of an inch or less (0.0002"). This is achieved on the 11-axis Star Lathe (as shown in Figure 7), which is comprised of two turning centers and several live tool centers that can be positioned to machine much like a mill. Typically, the only way to verify that the different tools are properly setup and synchronized to another is to cut a part and measure the features with respect to one another. This process is time consuming and the tools can be difficult to adjust based purely on inspection results. Traditionally, a practice part made out of brass or some other softer scrap material is machined and then verified $100 \%$ through Precision Measurement, comparator, gages, and/or hand micrometers. But once the practice part or production part is removed, it is virtually impossible to return the finished part to the same location and orientation in order to continue machining. Therefore, the operator only has one chance to cut a part correctly before the part is inspected. Figure 8 shows the multiple tool holder positions and turrets that are required for such a part. 


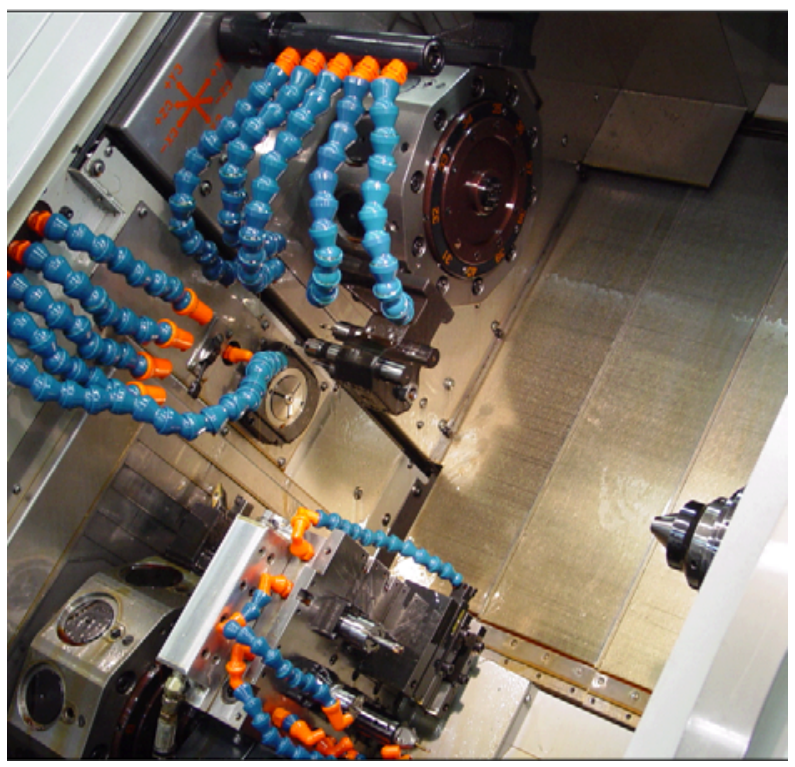

Figure 8: Department A Star Tool Holders and Live Tooling

The in-process CMM has the capability of providing the operator with accurate and instantaneous feedback based on the previously cut part. Thus, once the operator has properly set up the machine and is capable of running, only minor offset changes should be needed to compensate for tool wear and inexact setups. The quick turn around time associated with the in-process CMM eliminates the need for expensive gages or downtime waiting on first piece inspection from Precision Measurement. Figure 9 shows the features of the Plunger Valve that are critically orientated to one another as manufactured on the Star Lathe with live tooling as shown in Figure 8.
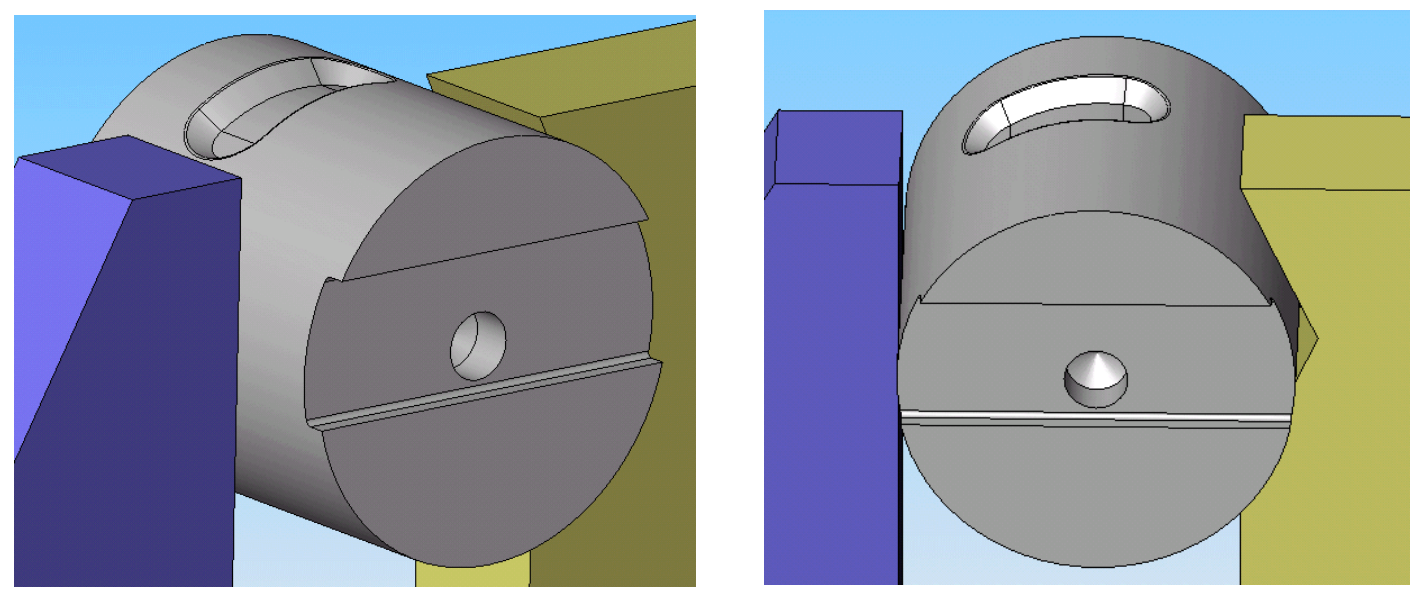

Figure 9: Solid Model of Plunger Valve 
The fixture and part were first modeled in SolidWorks and functionally proven using the off-line CMM programming software, Silma XG, for clearance and positioning. Based on the successful simulation in Silma, the actual fixture was fabricated to match the model size, shape, and function.

Figure 10 illustrates an example of the contact points where the probe touches the part in order to record values in the Silma software. The placement and orientation of these touch points coincides with the proper dimensioning of the part, known as Geometrical Dimensioning and Tolerancing (GD\&T).

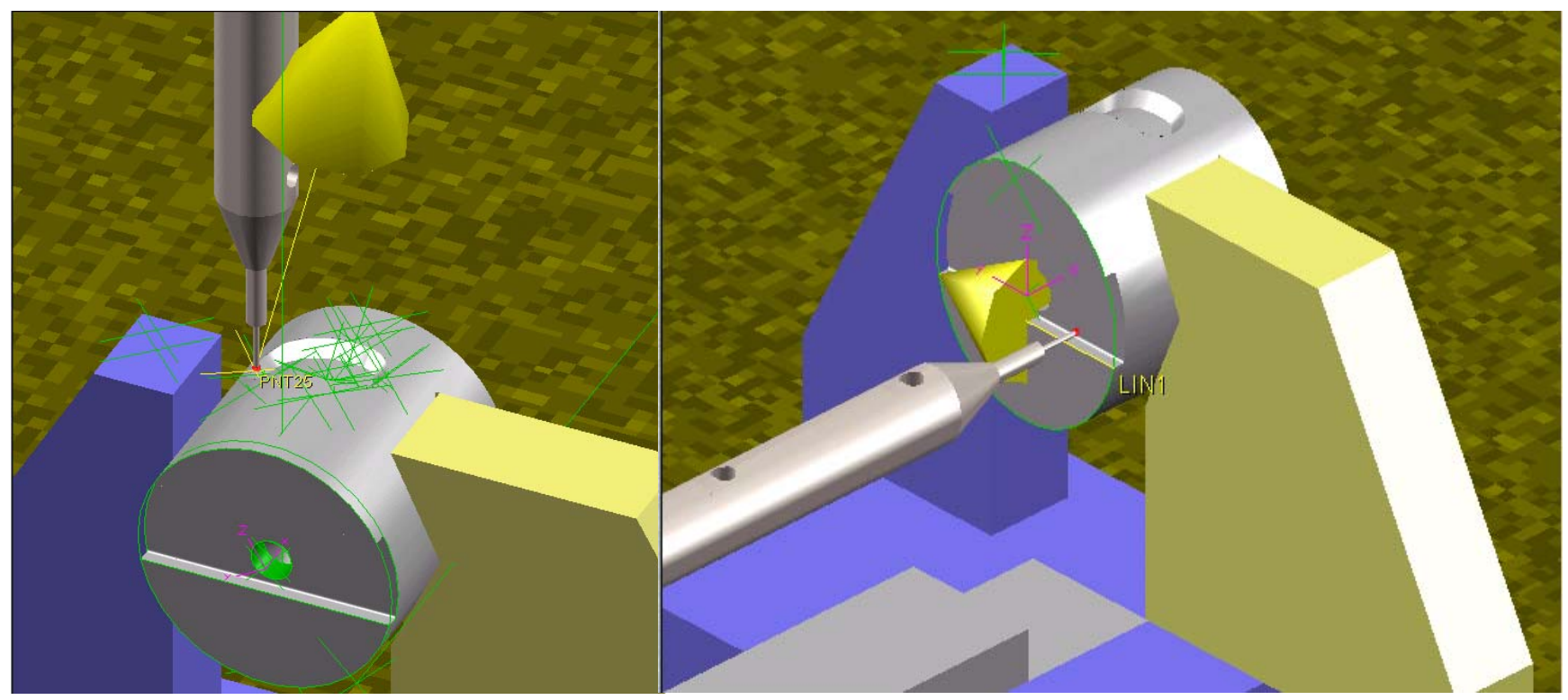

Figure 10: Silma XG Simulated Probe Touch Points

\section{Running CMM Programs}

The sole purpose of this ADAPT project was to implement a user-friendly CMM for operators to use on a regular basis. Typically engineers and machinists do not posses the in-depth training or technical know-how required to run a CMM, therefore clear and precise instructions are necessary. The procedures or instructions can be documented directly in the MES work instructions following a machining process, or as an attached word document such as a Special Work Instruction. Typically, an attached word document allows the engineer to go into further detail and to organize instructions with illustrations in order to connect with the operator. Upon opening an attached word document from MES, the operator can print off the instructions required to utilize the CMM. As an example, the following instructions shall cover the following procedures that are required to inspect products on the CMM. Future work will involve the standardization of special work instructions for all engineers to follow. 
Rough Outline:

1) Power up the CMM

2) Turn on the computer and log in

3) Load the required CMM program

4) Setup the fixture correctly

5) Calibrate the appropriate probe(s)

6) Run the CMM program

7) Interpret the results

\section{Example Program}

Once the procedures listed above are followed and the CMM program is opened, the program will prompt the operator to position the probe according to the illustration. Figure 11 is an example of a CMM prompt embedded in the program.

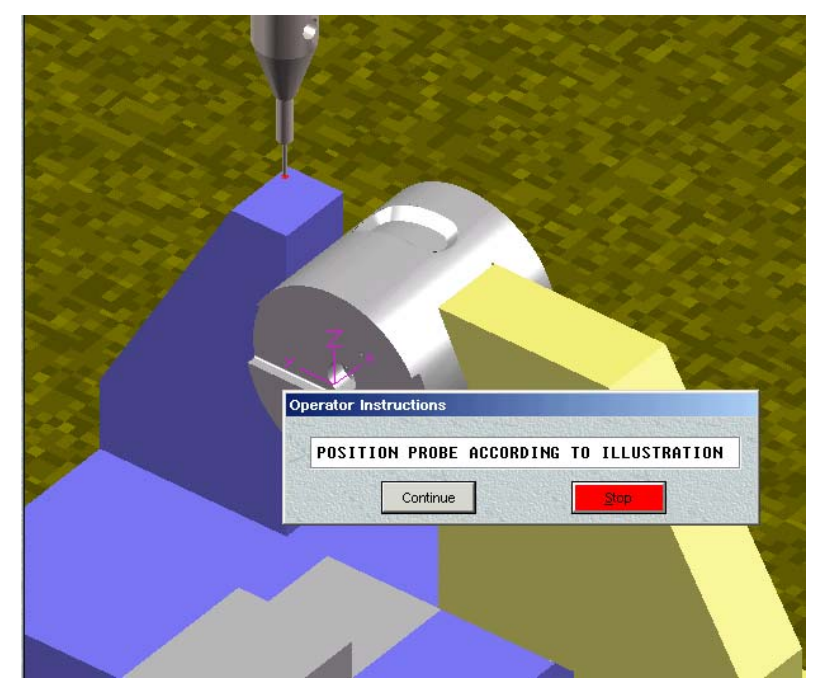

Figure 11: Silma XG Setup Prompt

Once the operator presses the continue button, another message will pop up on the computer monitor with an illustration to direct the operator to position the probe above an illustrated feature. The instructions and illustration are intended to ensure that the fixture is located in an approximate location that enables the program to find the exact location via an automated probing routine. Figure 12 shows an example of the positioning prompt popup illustration. 


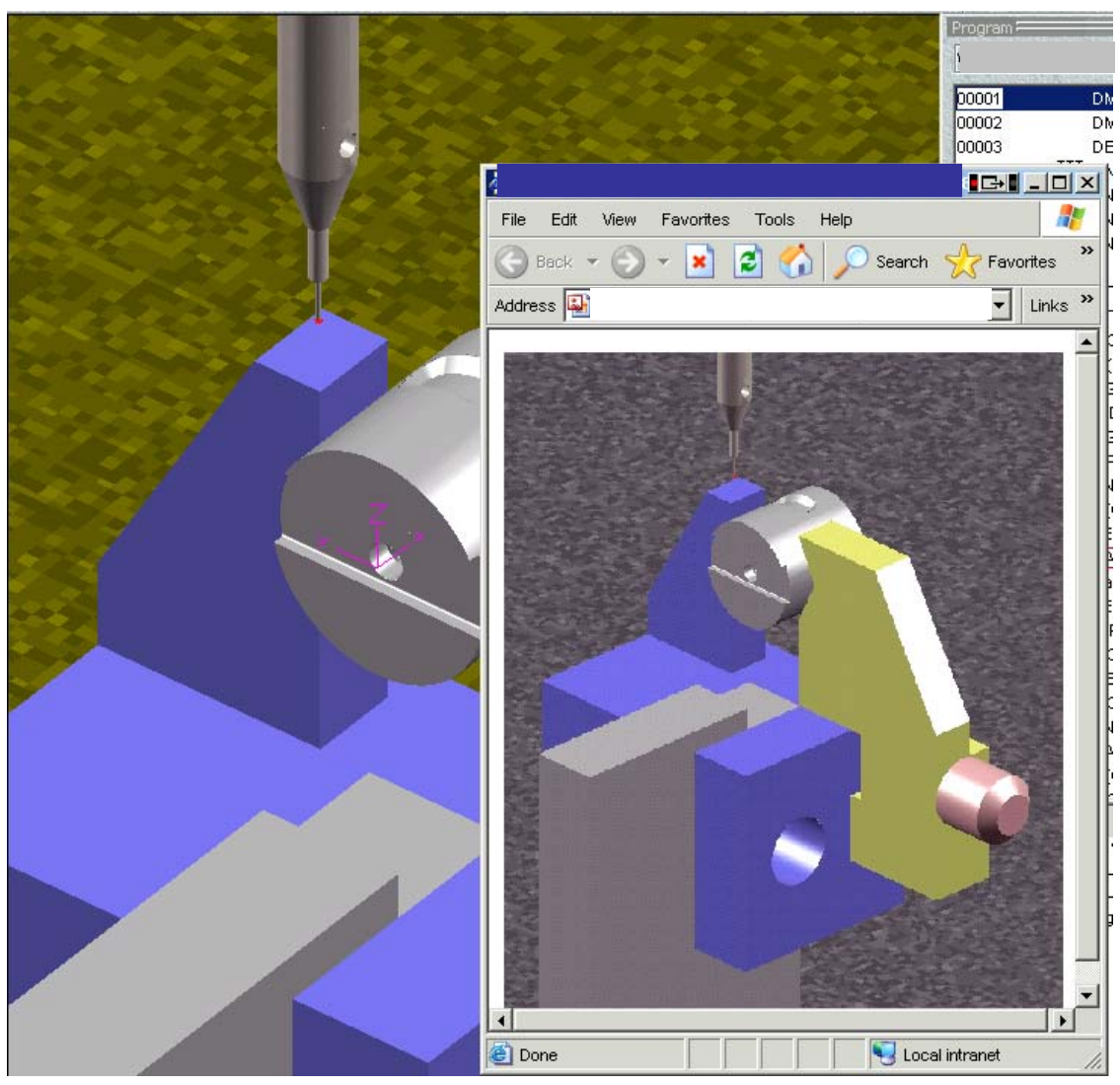

Figure 12: Silma XG Positioning Prompt Illustration

If the probe is in the correct position when the program starts the automated probing cycles, the CMM will perform a series of moves and probe touches that will locate the exact position of the fixture and part. At this point, the operator will not be required to perform any additional tasks until the CMM program is complete and all of the part features have been verified. For example, when the program begins the probing routines the CMM will move about the table in different directions and probing orientations in order to touch the various features. As a cautionary note, the operators are first instructed to run the program at a slower speed until they are familiar with the program.

Several probing touches are required in order to locate the part exactly. Once the fixture and part have been successfully located within the tolerance of the rough probing parameters, the part is then measured with many more points in multiple orientations to ensure that the true dimensions are captured. 
Figure 13 illustrates some of the probing points taken to locate and orientate the part coordinate system so that all proceeding points are based upon the actual position and orientation of the part. This ensures that all measurements are related to the same point on the part as shown on the drawing. This automated probing also ensures that multiple operators can place each part in roughly the same location knowing that the CMM will properly locate and orientate the part coordinate system for inspection.

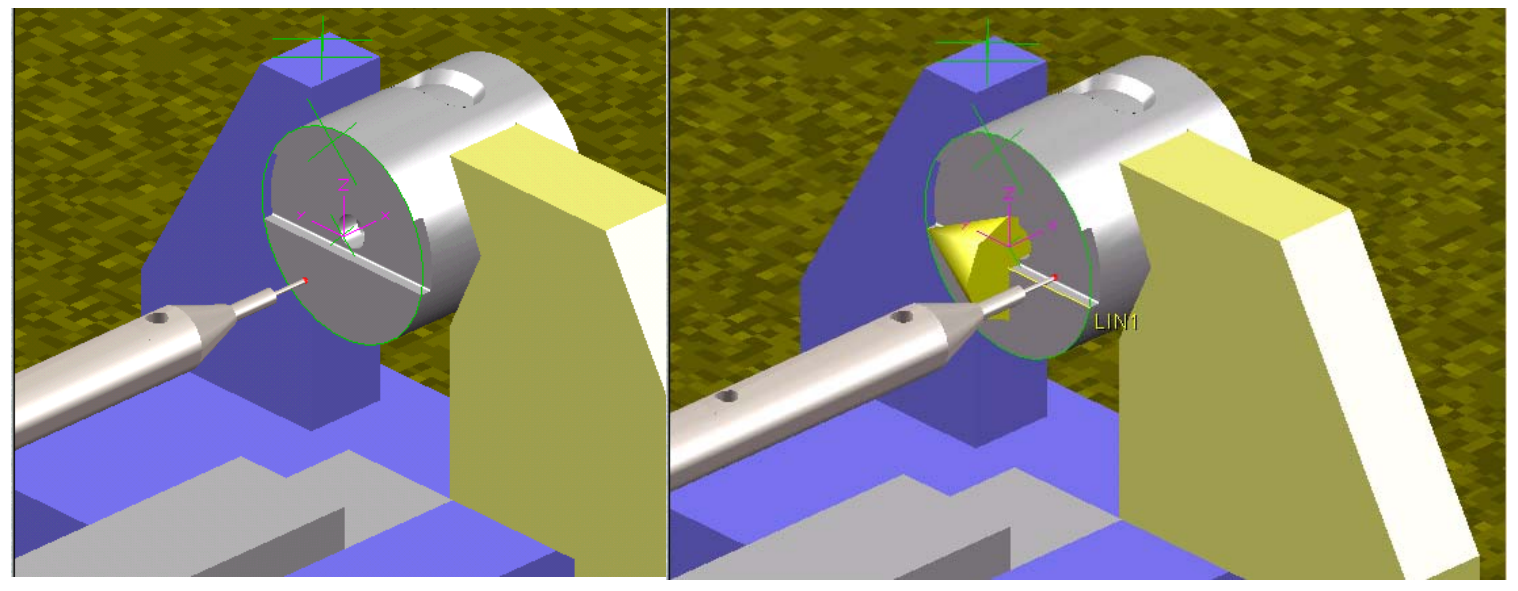

Figure 13: Silma XG Orientation Probing 


\section{Generating Reports}

An inspection report is available for each successful CMM program run in order for the operator to review the results. The optional Print Editor feature in Silma XG allows the engineer to customize the report in order to focus attention on certain features, illustrate problem areas, or make quick comparisons to Precision Measurement as shown below.

Figure 14 shows an example of the final report based upon the CMM inspection in the Silma software. Note, the values all show nominal dimensions based on the virtual size of the part as generated in SolidWorks. In contrast, when the same CMM program is run in Metrolog with a production part, the inspection results reflect the actual dimensions and deviations from nominal. The format and look of the report is standard on both Metrolog and Silma.

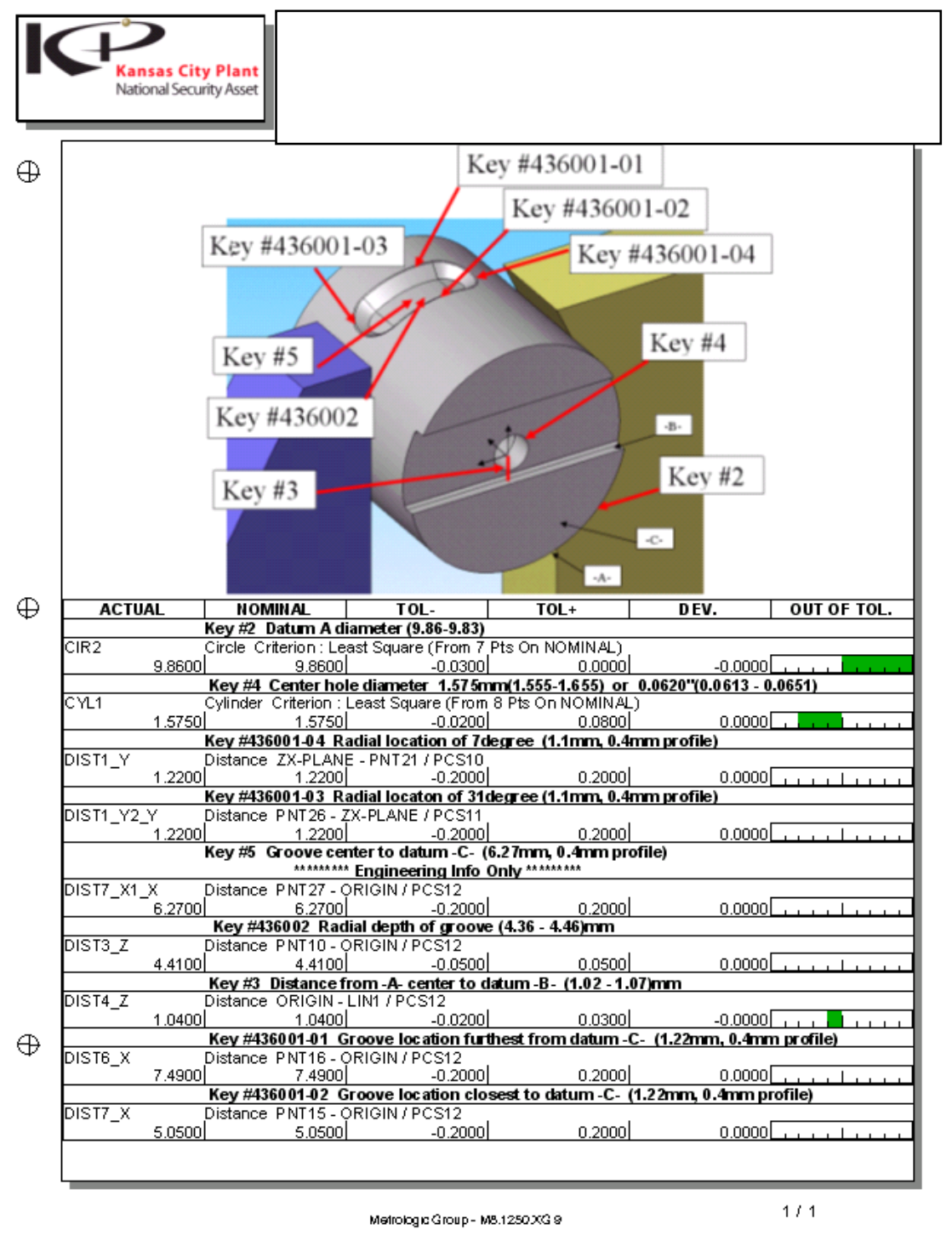

Figure 14: Silma XG CMM Report 


\section{Technical Challenges}

Over the course of this project (FY08), there have been a series of stability problems and repeatability issues that have limited the implementation of this CMM in Department A. However, KCP maintenance and engineering personnel have learned a great deal about the design and operation of the Image 555 CMM by troubleshooting and repairing the ongoing problems throughout the project.

This CMM was originally setup in Department B for operators to use as an in-process verification tool. The initial setup in Department B was performed by trained technicians from Image Inc., maker of the Image 555. The relocation and setup in Department A was performed by KCP's maintenance and equipment personnel who have a broad range of experience in working on CMMs of all sizes and makes. Therefore, KCP's equipment personnel do not possess the same level of understanding and technical know-how for installing and setting up this particular type of CMM as do that of the Image Inc. technical representatives. In retrospect it would have been helpful to employ the trained technicians from Image Inc. However, the troubles encountered thus far have provided KCP's maintenance personnel with a much better understanding of how this CMM works and what things can go wrong.

In Department B, the CMM was located on a dedicated concrete pad that isolated vibrations from adjacent machining equipment such as lathes, mills, and grinders. However, there were still repeatability problems as a result of vibrations through the airline that was hooked up to the CMM via copper piping. This problem was fixed by using a flexible hose that eliminated the vibrations from the copper pipe to the CMM. The installation in Department A is somewhat different in that the CMM is sitting on the same floor as a series of turning machines. Therefore, vibrations generated from the turning equipment are transmitted through the floor to the CMM, effecting the repeatability and accuracy. With the help of an equipment engineer, Department A was able to economically isolate the machining vibrations with a set of rubber/foam pads placed under the four legs of the CMM. The first attempt in using cushioned pads or vibration dampeners failed because they were too soft and caused the CMM to sway in all directions depending upon probe head movement. As a result, a firmer set of pads where installed which reduced the top-heavy swaying motion but absorbed less of the machining vibrations. The remedial fix was to slow the machine traverse speeds down in order to reduce the top-heavy sway motion and to use a mildly firm set of pads in order to isolate as much vibration as possible. At this point, the machine was initially calibrated and released for engineering use.

After six months of light developmental use, the standard machine calibration control date had expired on the Image 555 which prompted a second calibration procedure. During the second calibration procedure, the repeatability failed, which prompted maintenance personnel to test the Renishaw probe head for damage. The probe head was sent off to Renishaw for inspection and repaired. In the mean time, a backup probe head was ordered in the event that this particular situation arose in the future where product 
was dependent upon an in-process verification tool. Therefore, two working probe heads are now available for this CMM.

Despite having a new probe head, the repeatability continued to fail which prompted additional help from maintenance and engineering personnel. In order to isolate the problem to one particular moving component a new set of calibration programs where developed by a NC Analyst. The analyst was able to write a program for the CMM to perform a series of linear tests in each of the $\mathrm{X}, \mathrm{Y}$, and $\mathrm{Z}$ planes which helped identify the source of the problem. Because the machine moves on linear slides in the $\mathrm{X}, \mathrm{Y}$, and $\mathrm{Z}$ direction the additional programs helped to identify and calibrate each of the three axis after adjustment where made. These troubleshooting programs are now embedded in the main calibration program for maintenance personnel to use when necessary.

The source of the problem was identified by using the troubleshooting programs for the $\mathrm{X}, \mathrm{Y}$, and $\mathrm{Z}$ planes. It was determined that the repeatability in the XZ plane was out of tolerance because one of the air bearings was too tight, causing excessive drag and inconsistent movement across the horizontal linear slide. There are a total of five air bearings along the horizontal linear slide, each of which can be adjusted to affect the $X$, $\mathrm{Y}$, and $\mathrm{Z}$ planes. With all five air bearings rechecked and adjusted, the repeatability problem was fixed and the machine was again calibrated and released for use.

There were many lessons learned throughout the repair process for the engineers and maintenance personnel involved. Upon release, the CMM repeatability and accuracy showed significant signs of improvement as a result of a better understanding for how the CMM properly functions. The calibration procedures as well as this technical document capture some of the many challenges and fixes that took place and that ultimately lead to the repair of the machine.

\section{Summary of Accomplishments}

The goal of this project was to implement a user-friendly CMM into Department A for operators to check their machining work on a routine basis. Due to time constraints and unforeseen technical difficulties with the equipment a complete implementation and testing period with an operator was not possible. However, a great deal of work has been accomplished and documented for future development.

The following accomplishments coincide with the attached information in the appendices A and B. All of the programming, part files, and project details have been included as a reference for the following accomplishments. This document shall serve as a reference for future development and implementation work. The accomplishments and lessons learned have prepared KCP's engineers and maintenance personnel for future work. 


\section{$\underline{\text { Installation }}$}

The installation was a success in that the machine has been completely relocated from Department B to Department A. This involved several equipment and facilities engineers as well as maintenance technicians.

\section{Metrolog and Silma CMM Software Training}

Several engineers and operators were exposed to a five day training course that outlined the basics of CMM programming using both Metrolog and Silma XG. This training was taught by a professional from Metrologic Group Inc.

\section{Calibration Procedures}

The CMM calibration procedures were setup with the help of programming; an electronic technician; and metrology. A metrology engineer is the owner of the calibration procedure which documents and controls the appropriate programs, calibration blocks, and procedures required to calibrate a CMM. The metrology department is in charge of establishing calibration procedure standards used throughout the plant for various CMMs such as the Image 555 in Department A.

\section{Fixture Design and Fabrication}

An immediate need for a specific fixture required the design and fabrication of a dual use or dual purpose fixture. The fixture design has been illustrated in previous sections for the Plunger Valve and the 2Z Piston Valve. The custom design of the fixture allows several features to be inspected during one setup. This reduces the complexity of the process and the inspection time between parts. The cost of the custom designed fixture was reasonable $\sim \$ 1,500$ and the fabrication took place at KCP in a relatively short time frame.

\section{Troubleshooting and Technical Know-How}

Throughout the installation and implementation several unforeseen technical challenges have popped up requiring additional technical support. The engineers and maintenance personnel involved in solving the various repeatability problems have learned a great deal about the design and function of this particular CMM. Through trial/error and with the help of additional programming, the maintenance personnel were able to make proper adjustments to compensate for vibrations and unbalanced air bearings. 


\section{Software License Updates and Upgrades}

The CMM software packages Metrolog XG and Silma XG both have received updates from the vendor for the latest release as part of the software maintenance support paid for by this project and KCP's IT department. The Metrolog XG license was purchased for FY08 in which this project was activated. The Silma XG license was purchased by the IT department for the same period of time. Upgrades to the software include new releases for the following versions of software.

\begin{tabular}{llll} 
& Version & & Date \\
\cline { 2 - 2 } Metrolog and Silma XG & & $10 / 07$ \\
& V8.01 & $2 / 08$ \\
& V9.01 & $7 / 08$ \\
Opt. Silma XG Print Editor & V9.01 & $7 / 08$
\end{tabular}

\section{Future Work}

The full implementation of this CMM requires continual engineering support and operator usage in order to make this a valuable tool for Department A. There are several active programs that have products in Department A that use gages and precision measurement that could some day benefit from an in-process inspection tool such as this CMM.

Re-processing old products and new product development work requires a lot of inspection support via gages or precision measurement CMMs. Thus, with the implementation of this new equipment in Department A, engineers will be able to test new machining processes and reduce costs on gage designs.

\section{Future Training}

In order to continue to implement this CMM in Department A. more engineers and operators will need to be trained on how to program and operate the CMM. Additional training can be attained from Metrologic Group Inc., but a great deal of training and information sharing can be derived from the personnel involved.

The benefit of the off-line Silma programming software can be very helpful to engineers from one department to another through the use of the floating license. The immediate plan will be to promote this new technology to new hires that are lightly loaded and looking for new projects to generate a cost savings by reducing cycle times and improving yields for products. 


\section{Program Control and Documentation}

In the same way that the CNC programs are stored on the network for operators to download when needed, a similar system will need to be setup for the in-process CMM programs. The storage and control of the latest CMM program issues will most likely be controlled and monitored with the help of the NC Analysts group under a technical manager. Ideally, CMM programs will be accessible by the operator through a controlled system such as the DNC software. The crucial features of a controlling system will ensure that the operator is using the most current program and that key programming functions cannot be manipulated to alter results.

\section{Manufacturing Buy-off}

In the future, manufacturing may be able to inspect and perform the final buy-off for products inspected on the Image 555 CMM in Department A. The key challenges will be the calibration and program documentation procedures, adequate operator training, and a revision to some of KCPs business practices. Typically, most products are inspected and accepted by precision measurement, which is an unbiased third party group of CMM operators that have years of programming experience and a greater understanding of GD\&T. In order for an operator to buy off products using a manufacturing CMM, a considerable amount of control and documentation will be required to ensure that defective parts are not accepted.

\section{Classified Network}

Previously in Department B, this CMM was utilized for both unclassified and classified inspection. In Department A, the CMM is located in an unclassified area which prevents the CMM from being used to inspect classified products. Typically products that have contours, splines, and difficult to machine features are classified. Thus, these complex features make the in-process CMM a valuable tool for inspecting features that require either expensive and complex gages or precision measurement support. 


\title{
Appendix A - Programming and Product Definitions
}

\section{Silma/Metrolog CMM Program}

\author{
Plunger Valve
}

\begin{tabular}{|c|c|}
\hline 00001 & DMISMNA'BASE' \\
\hline 00002 & DMESWUICOMAND, 'NEW'WORKSESSION' \\
\hline 00003 & DECPLIDIST, 5,DEV, 4, TEMP, 1, ANGLE, 3 \\
\hline 00004 & III UNITSimm, ANGDEC, TEMPC \\
\hline 00005 & III SNSET/APPRCH,0.25 \\
\hline 00006 & III SNSET/SEARCH,0.05 \\
\hline 00007 & III SNSET/RETRCT,0.250 \\
\hline 00008 & $\$$ Delete PROG from line below when on CMM \\
\hline 00009 & 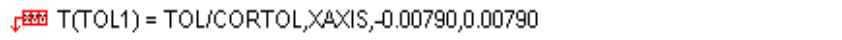 \\
\hline 00010 & $\sqrt{2 \times 7} \mathrm{~T}(\mathrm{TOL} 2)=$ TOL/CORTOL,YAXIS,-0.00790,0.00790 \\
\hline 00011 & 哭 MODElprog, MAN \\
\hline 00012 & (2) G(CAD)=GEOM/MODEL,'A=iadiuserfilesiu60911 ipubliciMetrolog \$ \\
\hline 00013 & XGID9312379881237988asm.su3' \\
\hline 00014 & SID(PLP)=DEVICE/STOR,'C:IProgram FilesiMetrologic GroupiMetrolog \$ \\
\hline 00015 & XGIProbesislot3.plp' \\
\hline 00016 & $8 *$ OPENIDID(PLP),SNS \\
\hline 00017 & Q. SNSLCTISA $\left(3 \_A 0.0 \_B 0.0\right)$ \\
\hline 00018 & D.CAD_PART)=TRANSIXORIG,270.9355,YORIG,-403.1556,ZORIG, 447.1318 \\
\hline 00019 & [⿰⿷匚⿳丨コ丨⿱⿰㇒一⿱⿱⿰口口十讠 \\
\hline 00020 & CALLIEXTERN,SYS,'C:IProgram Filesilntemet Explorerivexplore exe', wait, $\$$ \\
\hline 00021 & 'Vad'userfilesiu60911 ipubliciMetrolog XG10932237988isetup.jpg' \\
\hline 00022 & 㽬 TEXTIOPER,'BEGIN AUTO PROBING' \\
\hline 00023 & 囯 $F(P N T 1)=F E A T I P O I N T, C A R T, 5.1740,6.6080,4.9850,0.000000,0.000000,1.000000$ \\
\hline 00024 & $\therefore \rightarrow$ GOTO $15.1740,6.6080,4.9850$ \\
\hline 00025 & MEASIPOINT,F(PNT1),0 \\
\hline 00026 & $\rightarrow$ GOTO $15.1740,6.6080,4.9850$ \\
\hline 00027 & L ENDMES \\
\hline 00028 & DATDEFIFA(PNT1),DAT(A) \\
\hline 00029 & D. D(CAD_PART2)=DATSETIDAT (A),XORIG,YORIG,ZORIG \\
\hline 00030 & 喿 MODEIPROG, MAN \\
\hline 00031 & 囯缶 $F(P N T 2)=F E A T / P O I N T, C A R T, 0.0000,0.0000,-0.8575,0.000000,0.000000,1.000000$ \\
\hline 00032 & MEASIPOINT,F(PNT2),1 \\
\hline 00033 & A.t. GOTON0.0000,0.0000,2.0435 \\
\hline 00034 & - PTMEAS/CART, $0.0000,0.0000,-0.8575,0.000000,0.000000,1.000000$ \\
\hline 00035 & GOTON0.0000,0.0000,2.0435 \\
\hline 00036 & L ENDMES \\
\hline 00037 & $\hookrightarrow$ WKPLANINZPLAN \\
\hline
\end{tabular}




\begin{tabular}{|c|c|}
\hline 00038 & $\uparrow_{\triangle} \mathrm{D}(\mathrm{PCS} 1)=T R A N S R O R I G, F A(P N T 2)$ \\
\hline 00039 & GOTON $0.0000,0.0000,0.3441$ \\
\hline 00040 & 目堊 F(PNT3)=FEAT/POINT,CART, $5.1740,-5.9724,0.1110,-1.000000,0.000000,0.000000$ \\
\hline 00041 & I) MEASIPOINT,F(PNT3),1 \\
\hline 00042 & F.w GOTO/ $8.0751,0.0000,0.3441$ \\
\hline 00043 & $\Rightarrow$ GOTOH-8.0751,-5.9724,0.1110 \\
\hline 00044 & - PTMEASICART,-5.1740,-5.9724,0.1110,-1.000000,0.000000,0.000000 \\
\hline 00045 & $\Rightarrow$ GOTO/-8.0751,-5.9724,0.1110 \\
\hline 00046 & L ENDMES \\
\hline 00047 & ${ }^{\uparrow} \mathrm{D}(\mathrm{PCS} 3)=\mathrm{TRANSIXORIG,FA(PNT3)}$ \\
\hline 00048 & $\Rightarrow \rightarrow$ GOTO/-0.6853,-1.2323,0.1110 \\
\hline 00049 & 目㗌 $\mathrm{F}(\mathrm{CIR} 1)=\mathrm{FEAT} / \mathrm{CIRCLE}, \mathrm{OUTER}, \mathrm{CART}, 0.0000,-6.6080,-4.1275,1.000000,0.000000, \$$ \\
\hline 00050 & $0.000000,9.8600$ \\
\hline 00051 & I MEASICIRCLE,F(CIR1),5 \\
\hline 00052 & $\Rightarrow$ GOTOM $0.8000,-1.2323,-4.1275$ \\
\hline 00053 & PTMEASICART, $0.8000,-1.6780,-4.1275,0.000000,1.000000,0.000000$ \\
\hline 00054 & $m \rightarrow$ GOTON.8000,-1.2780,-1.1753 \\
\hline 00055 & $\rightarrow$ GOTON $8000,-2.8391,-0.3587$ \\
\hline 00056 & - PTMEAS/CART, $0.8000,-3.1220,-0.6415,0.000000,0.707107,0.707107$ \\
\hline 00057 & $\Rightarrow$ GOTO $0.8000,-3.3714,0.2383$ \\
\hline 00058 & $\Rightarrow \rightarrow$ GOTO $0.8000,-4.5282,0.8935$ \\
\hline 00059 & $\cdots$ GOTON $0.8000,-5.8095,1.2482$ \\
\hline 00060 & P PTMEAS/CART, $0.8000,-6.6080,0.8025,0.000000,0.000000,1.000000$ \\
\hline 00061 & $\cdots$ GOTO $0.8000,-7.4065,1.2482$ \\
\hline 00062 & $\rightarrow$ GOTO $0.8000,-8.6878,0.8935$ \\
\hline 00063 & $\cdots$ GOTON.8000,-9.8446,0.2383 \\
\hline 00064 & - PTMEAS/CART, $0.8000,-10.0940,-0.6415,0.000000,-0.707107,0.707107$ \\
\hline 00065 & $\ldots$ GOTOM.8000,-12.1379,-1.8476 \\
\hline 00066 & - PTMEASICART, $0.8000,-11.5380,-4.1275,0.000000,-1.00000,0.00000$ \\
\hline 00067 & L ENDMES \\
\hline 00068 & $\AA_{\triangle} \mathrm{D}(\mathrm{PCS} 4)=\mathrm{TRANS} N O R|\mathrm{G}, \mathrm{FA}(\mathrm{CIR} 1), Z O R| \mathrm{G}, \mathrm{FA}(\mathrm{CIR} 1)$ \\
\hline 00069 & $\Rightarrow \rightarrow$ GOTOl-16.0000,-5.3300,3.7000 \\
\hline 00070 & $\Rightarrow \rightarrow$ GOTOl-16.0000,-5.3300,50.0000 \\
\hline 00071 & Q. SNSLCT/SA(3_A90.0_B90.0) \\
\hline 00072 & $\rightarrow$ GOTO/ $8.9000,-4.0000,25.0000$ \\
\hline 00073 & 国 F(PLN1)=FEAT/PLANE,CART, $0.0000,0.0000,-1.0400,-1.000000,0.000000,0.000000$ \\
\hline 00074 & MEASIPLANE,F(PLN1),5 \\
\hline 00075 & N.w. GOTOL-0.6500,-2.6865,3.2258 \\
\hline
\end{tabular}




\begin{tabular}{|c|c|}
\hline 00076 & PTMEASICART, $0.0000,-2.6865,3.2258,-1.000000,0.000000,0.000000$ \\
\hline 00077 & PTMEASICART, $0.0000,2.6932,3.0790,-1.000000,0.000000,0.000000$ \\
\hline 00078 & PTMEAS/CART, $0.0000,3.2745,-2.0091,-1.0000000,0.000000,0.000000$ \\
\hline 00079 & PTMEAS/CART, $0.0000,0.2942,-3.6220,-1.000000,0.000000,0.000000$ \\
\hline 00080 & PTMEAS/CART, $0.0000,-2.8684,-1.8957,-1.000000,0.000000,0.000000$ \\
\hline 00081 & $=$ GOTOI-0.6500,-2.8684,-1.8957 \\
\hline 00082 & L ENDMES \\
\hline 00083 & DATDEF/FA(PLN1),DAT(A) \\
\hline 00084 & D $\mathrm{D}(\mathrm{PCS} 5)=\mathrm{DATSETIDAT}(\mathrm{A}),-\mathrm{XDIR}, \mathrm{XORIG}$ \\
\hline 00085 & 囯 F(LIN1)=FEAT/LINE,BND,CART,0.0000,-4.8190,-1.0400,0.0000,4.8191,-1.0400,\$ \\
\hline 00086 & $1.000000,0.000000,0.000000$ \\
\hline 00087 & of MEASILINE, $F(L \mid N 1), 3$ \\
\hline 00088 & H.t. GOTOL-0.6500,-2.8684,-0.4851 \\
\hline 00089 & $\ldots+$ GOTON $0.2413,-4.6691,-0.6401$ \\
\hline 00090 & - PTMEASICART,0.2413,-4.6691,-1.0400,0.0000000,0.0000000,1.000000 \\
\hline 00091 & - PTMEAS/CART,0.2413,0.0000,-1.0400,0.0000000,0.0000000,1.000000 \\
\hline 00092 & - PTMEASICART,0.2413,4.6691,-1.0400,0.0000000,0.0000000,1.000000 \\
\hline 00093 & $\Rightarrow$ GOTO $0.2413,4.6691,-0.6401$ \\
\hline 00094 & L ENDMES \\
\hline 00095 & ${ }_{\triangle} \mathrm{D}(\mathrm{PCS} 1)=\mathrm{ROTATE} / \mathrm{XAXIS,FA(LIN1),YDIR}$ \\
\hline 00096 & A* GOTOL-3.0000,-5.0000,-2.0000 \\
\hline 00097 & 囯 $F(C I R 2)=F E A T / C I R C L E, O U T E R, C A R T, 0.5300,0.0000,-0.0000,1.000000,0.000000, \$$ \\
\hline 00098 & $-0.000000,9.8600$ \\
\hline 00099 & MEASICIRCLE,F(CIR2),7 \\
\hline 00100 & W.t. GOTOM $2800,-4.9488,-1.9795$ \\
\hline 00101 & - $\quad$ PTMEASICART, $1.5300,-4.5774,-1.8310,0.000000,-0.928479,-0.371384$ \\
\hline 00102 & $m$ GOTOM $.5300,-4.5980,-2.8974$ \\
\hline 00103 & WF GOTOM $.5300,-3.6706,-4.0079$ \\
\hline 00104 & $\ldots$ GOTOM $.5300,-2.4830,-4.8344$ \\
\hline 00105 & - $\quad$ PTMEASICART, $1.5300,-1.4225,-4.7204,-0.000000,-0.288539,-0.957468$ \\
\hline 00106 & $\cdots$ GOTOM $.5300,-0.6016,-5.4014$ \\
\hline 00107 & $=\rightarrow$ GOTOM $.5300,0.8449,-5.3687$ \\
\hline 00108 & $\Rightarrow$ GOTOM $.5300,2.2315,4.9555$ \\
\hline 00109 & - PTMEAS/CART, $1.5300,2.8036,-4.0553,-0.000000,0.568677,-0.822561$ \\
\hline 00110 & $\Rightarrow$ GOTOM $.5300,3.8479,-3.8381$ \\
\hline 00111 & $\Rightarrow$ GOTOM $.5300,4.7242,-2.6868$ \\
\hline 00112 & $\rightarrow$ GOTOM $.5300,5.2657,-1.3451$ \\
\hline 00113 & - PTMEASICART, $1.5300,4.9185,-0.3365,-0.000000,0.997668,-0.068250$ \\
\hline
\end{tabular}




\begin{tabular}{|c|c|}
\hline 00114 & GOTOM. $5300,5.3998,0.6154$ \\
\hline 00115 & $\cdots$ GOTOM $1.5300,5.0461,2.0183$ \\
\hline 00116 & W.: GOTOM. $5300,4.3347,3.2782$ \\
\hline 00117 & - PTMEASICART,1.5300,3.3297,3.6356,0.0000000,0.675397,0.737454 \\
\hline 00118 & $\cdots$ GOTOM. $5300,2.8856,4.6054$ \\
\hline 00119 & $\cdots$ GOTOM $1.5300,1.5682,5.2036$ \\
\hline 00120 & $\cdots$ GOTOM $.5300,0.1396,5.4329$ \\
\hline 00121 & - $\quad$ PTMEAS/CART, $1.5300,-0.7664,4.8700,0.000000,-0.156460,0.987842$ \\
\hline 00122 & $\ldots$ GOTOM. $5300,-1.8015,5.1274$ \\
\hline 00123 & $\Rightarrow \rightarrow$ GOTOM.5300,-3.0906,4.4704 \\
\hline 00124 & $\cdots$ GOTOM $5300,-4.1606,3.4965$ \\
\hline 00125 & - PTMEASICART, $1.5300,-4.2854,2.4372,0.000000,-0.869253,0.494367$ \\
\hline 00126 & $=$ GOTOM $2800,-4.6331,2.6349$ \\
\hline 00127 & L ENDMES \\
\hline 00128 & $\sqrt{2 \times 27}$ T(CIR2_D|AM) $=T O L / D \mid A M,-0.0300,0.0000$ \\
\hline 00129 & F OUTPUTIFA(CIR2),TA(CIR2_DIAM) \\
\hline \multicolumn{2}{|l|}{00130} \\
\hline 00131 & $\therefore \rightarrow$ GOTOL-3.0000,-5.0000,-2.0000 \\
\hline 00132 & $\$$ \\
\hline 00133 & ${ }_{\triangle \triangle} \mathrm{D}(\mathrm{PCS} 7)=\mathrm{TRANS} Y \mathrm{YRIG}, \mathrm{FA}(\mathrm{CIR} 2), \mathrm{ZORIG,FA}(\mathrm{CIR} 2)$ \\
\hline 00134 & a't GOTO/-2.0000,3.1905,0.0000 \\
\hline 00135 & ;w' GOTOH $-1.3930,0.0000,0.0000$ \\
\hline 00136 & 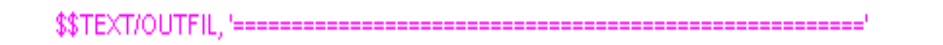 \\
\hline 00137 & F TEXTIOUTFIL,'Key \#2 Datum A diameter (9.86-9.83) ' \\
\hline 00138 & 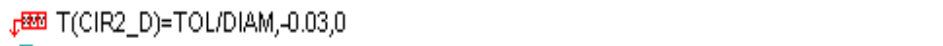 \\
\hline 00139 & 浒 OUTPUTIFA(CIR2),TA(CIR2_D) \\
\hline 00140 & 目 $F(C Y L 1)=F E A T / C Y L N D R, I N N E R, C A R T, 0.5300,0.0000,0.0000,1.000000,0.000000,0.000000, \$$ \\
\hline 00141 & $1.5750,1.0253$ \\
\hline 00142 & MEASICYLNDR,F(CYL1),8 \\
\hline 00143 & F." GOTO0.6800,0.3864,0.0289 \\
\hline 00144 & - PTMEAS/CART, $0.6800,0.7853,0.0589,0.000000,-0.997197,-0.074822$ \\
\hline 00145 & - $\quad$ PTMEASICART, $0.6800,-0.0589,0.7852,-0.000000,0.074822,-0.997197$ \\
\hline 00146 & - PTMEASICART, $0.6800,-0.7853,-0.0590,-0.000000,0.997197,0.074822$ \\
\hline 00147 & - PTMEAS/CART, $0.6800,0.0589,-0.7853,0.000000,-0.074822,0.997197$ \\
\hline 00148 & - PTMEAS/CART, $1.4053,0.7853,0.0589,0.000000,-0.997197,-0.074822$ \\
\hline 00149 & - $\quad$ PTMEASICART, $1.4053,-0.0589,0.7852,-0.000000,0.074822,-0.997197$ \\
\hline 00150 & - $\quad$ PTMEAS/CART, $1.4053,-0.7853,-0.0590,-0.000000,0.997197,0.074822$ \\
\hline 00151 & - PTMEAS/CART, $1.4053,0.0589,-0.7853,0.000000,-0.074822,0.997197$ \\
\hline
\end{tabular}




\begin{tabular}{|c|c|}
\hline 00152 & $\ldots \rightarrow$ GOTON0.6800,0.0290,-0.3865 \\
\hline 00153 & L ENDMES \\
\hline 00154 & 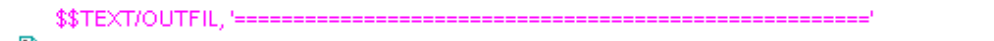 \\
\hline 00155 & 呞 TEXTIOUTFIL,' Key \#4 Center hole diameter $1.575 \mathrm{~mm}(1.555-1.655)$ or $0.0620 "(0.0613-0.0651)$ \\
\hline 00156 & $\sqrt{2 \times m} T(T O L 4)=T O L / D \mid A M,-0.02,0.08$ \\
\hline 00157 & 辟 OUTPUTIFA(CYL1),TA(TOL4) \\
\hline 00158 & $\therefore \cdots \rightarrow$ GOTOL $-0.8550,0.0000,-0.3860$ \\
\hline 00159 & $\therefore \cdots$ GOTOI-4.5000,0.0000,72.0000 \\
\hline 00160 & Q. SNSLCTISA(3_AOD.0_BO.0) \\
\hline 00161 & $\therefore \rightarrow$ GOTOI-0.5000,0.0000,8.0000 \\
\hline 00162 & $\$ \$$ Start profile of groove \\
\hline 00163 & 目国 F(PNT4)=FEAT/POINT,CART,1.4259,0.0000,-4.9289,-0.000000,0.000000,1.000000 \\
\hline 00164 & MEASIPOINT,F(PNT4),1 \\
\hline 00165 & $\Rightarrow$ GOTOM $1865,0.0000,7.8215$ \\
\hline 00166 & - PTMEASICART,1.1865,0.0000,4.9204,0.000000,0.000000,1.000000 \\
\hline 00167 & $\cdots$ GOTOM.1865,0.0000,7.8215 \\
\hline 00168 & L ENDMES \\
\hline 00169 & 圆 F(PNT5)=FEATIPOINT,CART,3.7891,0.0000,4.9273,0.000000,0.000000,1.000000 \\
\hline 00170 & MEASIPOINT,F(PNT5),1 \\
\hline 00171 & $\Rightarrow$ GOTOB.7891,0.0000,7.8284 \\
\hline 00172 & - PTMEASICART,3.7891,0.0000,4.9273,0.000000,0.000000,1.000000 \\
\hline 00173 & $\ldots+$ GOTOB $3.7891,0.0000,7.8284$ \\
\hline 00174 & L ENDMES \\
\hline 00175 & 目国 F(LIN2)=FEAT/LINE,BND,CART,1.1865,0.0000,4.9204,3.7891,0.0000,4.9273,0.000000,\$ \\
\hline 00176 & $1.000000,0.000000$ \\
\hline 00177 & CONST/LINE,F(LIN2),BF,FA(PNT4),FA(PNT5) \\
\hline 00178 & 目 $\mathrm{F}$ (PNT6)=FEATIPOINT,CART,5.12767,0.00000,4.84482,0.707107,0.000000,0.707107 \\
\hline 00179 & F' MEASIPOINT,F(PNT6),1 \\
\hline 00180 & $\ldots+$ GOTO $5.6147,0.0000,5.2844$ \\
\hline 00181 & - PTMEAS/CART,5.12767,0.00000,4.84482,0.707107,0.000000,0.707107 \\
\hline 00182 & $\ldots \rightarrow$ GOTO $5.6147,0.0000,5.2844$ \\
\hline 00183 & L ENDMES \\
\hline 00184 & 目国 $\mathrm{F}(\mathrm{PNT})=\mathrm{FEAT}$ /POINT,CART,5.44586,0.00000,4.52663,0.707107,0.000000,0.707107 \\
\hline 00185 & MEASIPOINT,F(PNTT),1 \\
\hline 00186 & ....; GOTO16.0927,0.0000,5.1615 \\
\hline 00187 & - PTMEASICART,5.44586,0.00000,4.52663,0.707107,0.000000,0.707107 \\
\hline 00188 & $\cdots$ GOTON6.0927,0.0000,5.1615 \\
\hline 00189 & L ENDMES \\
\hline
\end{tabular}




\begin{tabular}{|c|c|}
\hline 00190 & 目国 F(LIN3)=FEATILINE,BND,CART,5.12767,0.00000,4.84482,5.44686,0.00000,4.52663,\$ \\
\hline 00191 & $0.000000,1.000000,0.000000$ \\
\hline 00192 & Fin: CONSTILINE,F(LIN3),BF,FA(PNT6),FA(PNT7) \\
\hline 00193 & 目 F(PNT9)=FEAT/POINT,CART, $5.78160,0.00000,4.41000,0.000000,0.000000,1.000000$ \\
\hline 00194 & MEASIPOINT,F(PNTS),1 \\
\hline 00195 & $\cdots$ GOTO $5.7816,0.0000,5.0563$ \\
\hline 00196 & - PTMEAS/CART,5.78160,0.00000,4.41000,0.000000,0.000000,1.000000 \\
\hline 00197 & $\ldots$ GOTO $5.7816,0.0000,5.0553$ \\
\hline 00198 & ENDMES \\
\hline 00199 & 圄 F(PNT10)=FEAT/POINT,CART,6.70530,0.00000,4.41000,0.000000,0.000000,1.000000 \\
\hline 00200 & MEASIPOINT,F(PNT10),1 \\
\hline 00201 & $\because$ GOTO $6.7053,0.0000,5.0598$ \\
\hline 00202 & - $\quad$ PTMEASICART,6.70530,0.00000,4.41000,0.000000,0.000000,1.000000 \\
\hline 00203 & $\Rightarrow$ GOTOI6.7053,0.0000,5.0598 \\
\hline 00204 & ENDMES \\
\hline 00205 & 目国 F(PNT11)=FEATIPOINT,CART, $7.03038,0.00000,4.46288,-0.707107,0.000000,0.707107$ \\
\hline 00206 & MEASIPOINT,F(PNT11),1 \\
\hline 00207 & $\rightarrow$ GOTO16.6370,0.0000,4.9946 \\
\hline 00208 & PTMEASICART,7.03038,0.00000,4.46288,-0.707107,0.000000,0.707107 \\
\hline 00209 & $\ldots$ GOTO $6.6370,0.0000,4.9946$ \\
\hline 00210 & ENDMES \\
\hline 00211 & 目国 F(PNT12)=FEATIPOINT,CART, $7.34858,0.00000,4.78108,-0.707107,0.000000,0.707107$ \\
\hline 00212 & MEASIPOINT,F(PNT12),1 \\
\hline 00213 & GOTO $6.8987,0.0000,5.2576$ \\
\hline 00214 & - $\quad$ PTMEASICART,7.34858,0.00000,4.78108,-0.707107,0.000000,0.707107 \\
\hline 00215 & $\Rightarrow$ GOTO $6.8987,0.0000,5.2576$ \\
\hline 00216 & L ENDMES \\
\hline 00217 & 目国 F(PNT13)=FEAT/POINT,CART, $7.7481,0.0000,4.9272,0.000000,0.000000,1.000000$ \\
\hline 00218 & MEASIPOINT,F(PNT13),1 \\
\hline 00219 & $\cdots \rightarrow$ GOTO $7.7481,0.0000,5.5772$ \\
\hline 00220 & - PTMEASICART,7.7481,0.0000,4.9272,0.000000,0.000000,1.000000 \\
\hline 00221 & $\cdots$ GOTO $7.7481,0.0000,5.5772$ \\
\hline 00222 & L ENDMES \\
\hline 00223 & 目国 F(PNT14)=FEAT/POINT,CART,8.7717,0.0000,4.9274,0.000000,0.000000,1.000000 \\
\hline 00224 & MEASIPOINT,F(PNT14),1 \\
\hline 00225 & . $\rightarrow$ GOTOR $8.7717,0.0000,5.5774$ \\
\hline 00226 & - PTMEAS/CART,8.7717,0.0000,4.9274,0.000000,0.000000,1.000000 \\
\hline 00227 & $\ldots$ GOTOR $8.7717,0.0000,5.5774$ \\
\hline
\end{tabular}




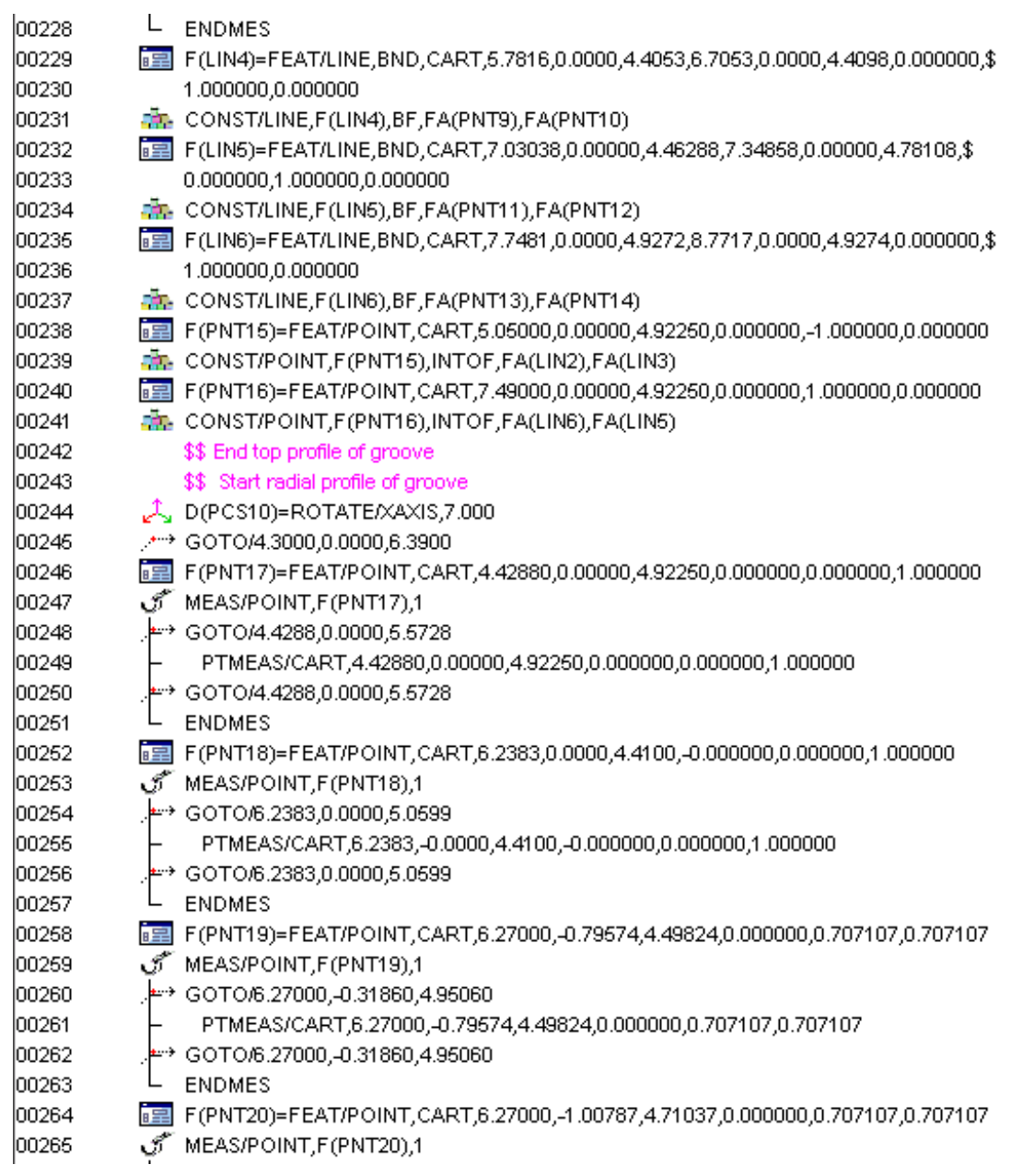




\begin{tabular}{|c|c|}
\hline 00266 & $\rightarrow$ GOTO $6.27000,-0.54110,5.17360$ \\
\hline 00267 & PTMEAS/CART,6.27000,-1.00787,4.71037,0.000000,0.707107,0.707107 \\
\hline 00268 & $\cdots$ GOTO $6.27000,-0.54110,5.17360$ \\
\hline 00269 & L ENDMES \\
\hline 00270 & 目旺 $\mathrm{F}(\mathrm{LIN} 7)=\mathrm{FEAT} / \mathrm{L}$ INE,BND,CART,6.27000,-0.79574,4.49824,6.27000,-1.00787,4.71037,\$ \\
\hline 00271 & $1.000000,0.000000,0.000000$ \\
\hline 00272 & CONSTILINE,F(LIN7),BF,FA(PNT19),FA(PNT20) \\
\hline 00273 & 目国 F(PLN2)=FEAT/PLANE,CART,4.42880,0.00000,4.92250,0.000000,0.000000,1.000000 \\
\hline 00274 & CONSTIPLANE,F(PLN2),PARTO,FA(XY-PLANE),THRU,FA(PNT17) \\
\hline 00275 & 目旺 F(PNT21)=FEATIPOINT,CART,6.27000,-1.22000,4.92250,0.000000,0.000000,1.000000 \\
\hline 00276 & CONSTIPOINT,F(PNT21),INTOF, FA(LIN7), FA(PLN2) \\
\hline 00277 & 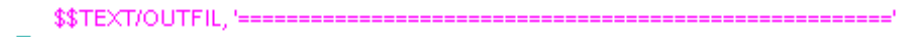 \\
\hline 00278 & 劻 TEXTIOUTFIL,'Key \#436001-04 Radial location of 7degree (1.1mm, $0.4 \mathrm{~mm}$ profile) ' \\
\hline 00279 & $\sqrt{2 \times 2}$ T(DIST1_Y)=TOLIDISTB,NOMINL,1.22000,-0.2000,0.2000,YAXIS \\
\hline 00280 & 缶 OUTPUTIFA(ZX-PLANE),FA(PNT21),TA(DIST1_Y) \\
\hline 00281 & $\$ \$$ \\
\hline 00282 & 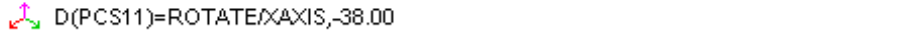 \\
\hline 00283 & $\therefore \rightarrow$ GOTO/4.2000,0.0000,6.0000 \\
\hline 00284 & 目旺 $\mathrm{F}(\mathrm{PNT} 22)=\mathrm{FEAT} / \mathrm{POINT}$,CART,4.19830,0.00000,4.92250,0.000000,0.000000,1.000000 \\
\hline 00285 & MEASIPOINT,F(PNT22),1 \\
\hline 00286 & GOTO/4.1983,0.0000,5.5145 \\
\hline 00287 & - PTMEASICART,4.19830,0.00000,4.92250,0.000000,0.000000,1.000000 \\
\hline 00288 & $\cdots$ GOTO/4.1983,0.0000,5.5145 \\
\hline 00289 & L ENDMES \\
\hline 00290 & 目国 F(PNT23)=FEAT/POINT,CART,6.2086,0.0000,4.4100,0.000000,0.000000,1.000000 \\
\hline 00291 & MEASIPOINT,F(PNT23),1 \\
\hline 00292 & $\cdots \rightarrow$ GOTOI6.2086,0.0000,5.0599 \\
\hline 00293 & PTMEASICART,6.2086,0.0000,4.4100,0.000000,-0.000000,1.000000 \\
\hline 00294 & $\rightarrow$ GOTO $6.2086,0.0000,5.0599$ \\
\hline 00295 & L ENDMES \\
\hline 00296 & 目旺 $\mathrm{F}$ (PNT24)=FEAT/POINT,CART,6.27000,0.79574,4.49824,0.000000,-0.707107,0.707107 \\
\hline 00297 & MEASIPOINT,F(PNT24),1 \\
\hline 00298 & $\ldots$ GOTOI6.27000,0.33500,4.96640 \\
\hline 00299 & PTMEASICART,6.27000,0.79536,4.49824,0.000000,-0.707107,0.707107 \\
\hline 00300 & $\Rightarrow$ GOTO $6.27000,0.33500,4.96640$ \\
\hline 00301 & L ENDMES \\
\hline 00302 & 目星 F(PNT25)=FEAT/POINT,CART,6.27000,1.00787,4.71037,0.000000,-0.707107,0.707107 \\
\hline 00303 & MEASIPOINT,F(PNT25),1 \\
\hline
\end{tabular}




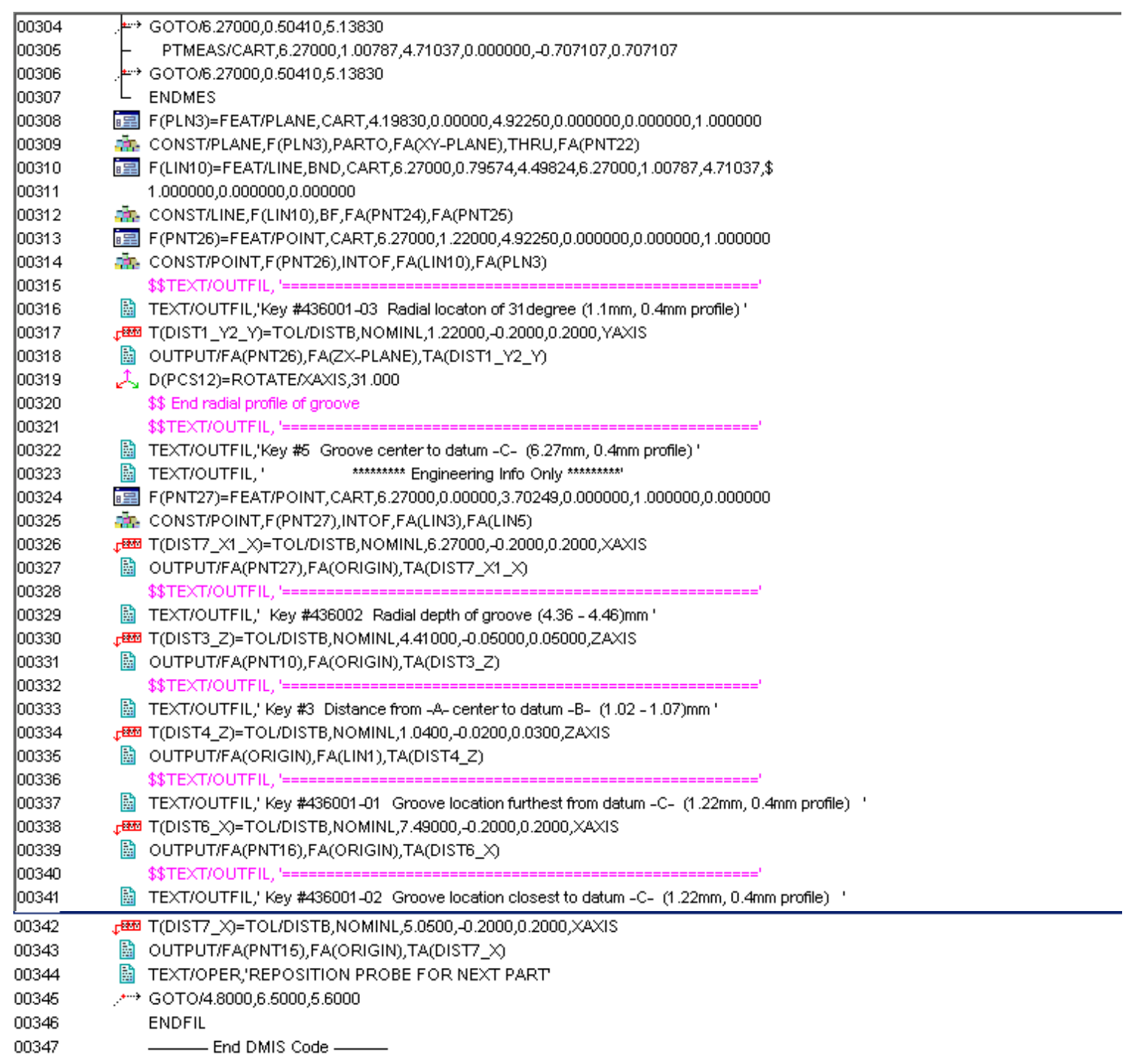




\section{Piston, 2Z Valve}

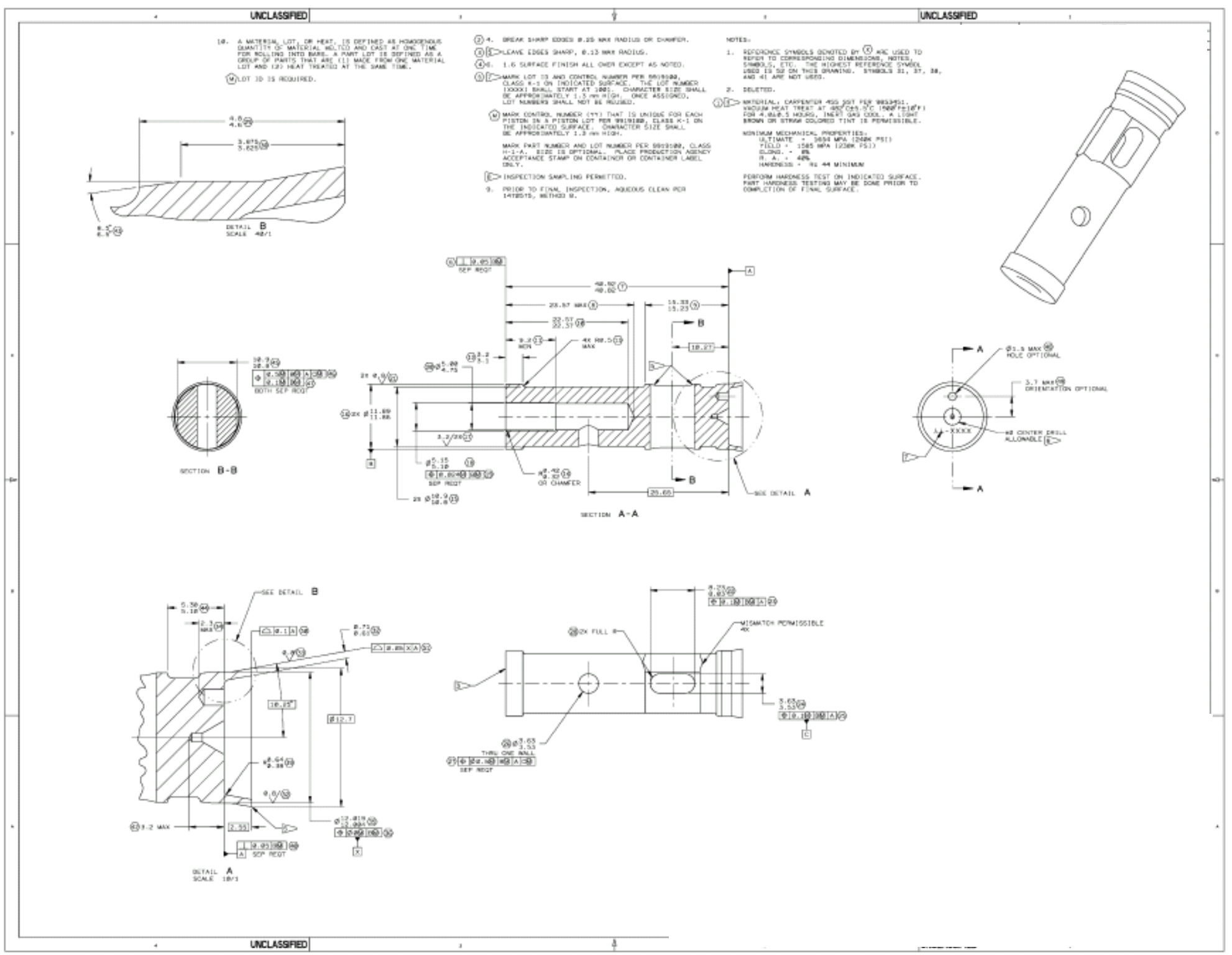




\section{Plunger Valve Part Drawing}

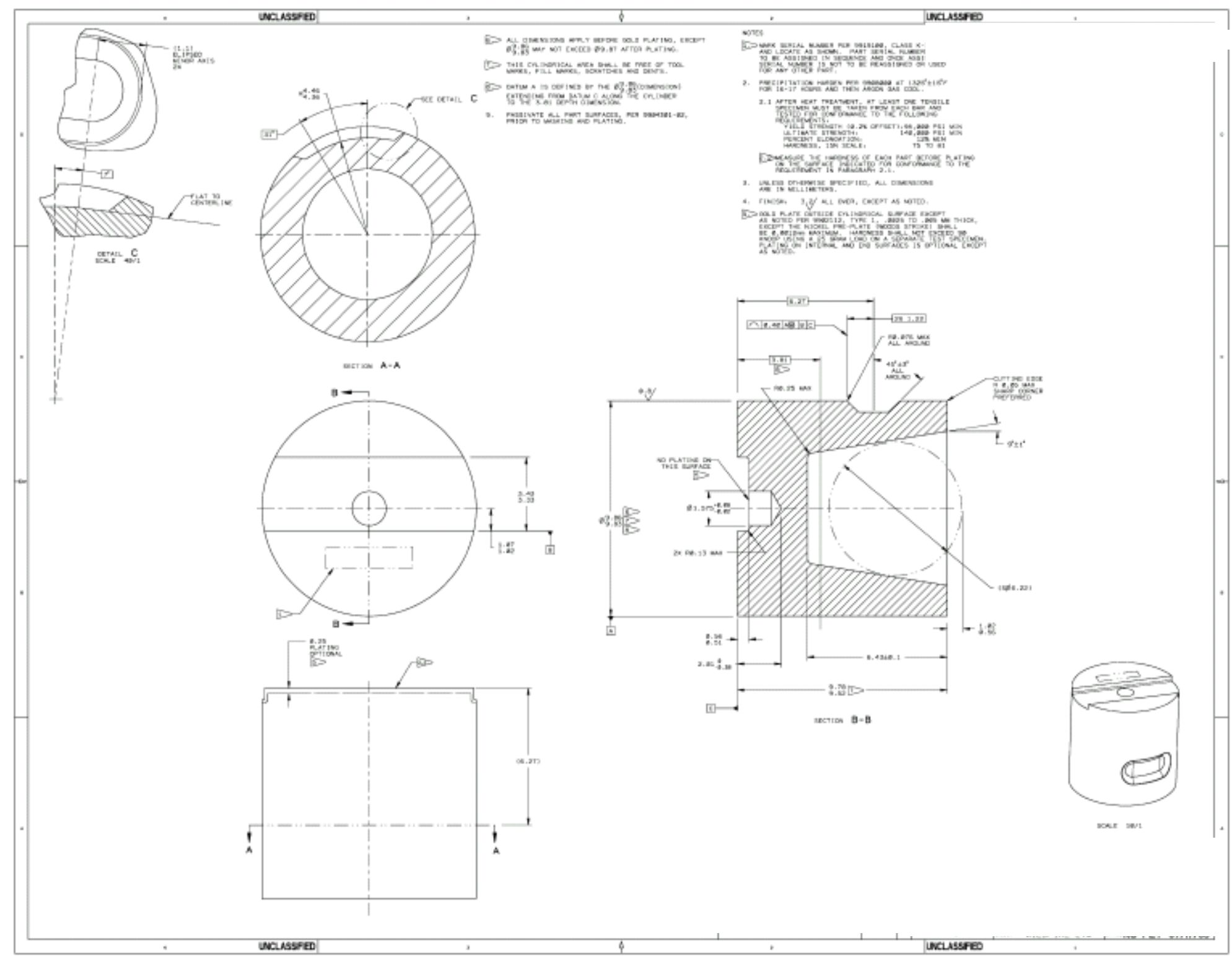




\section{Fixture Design}

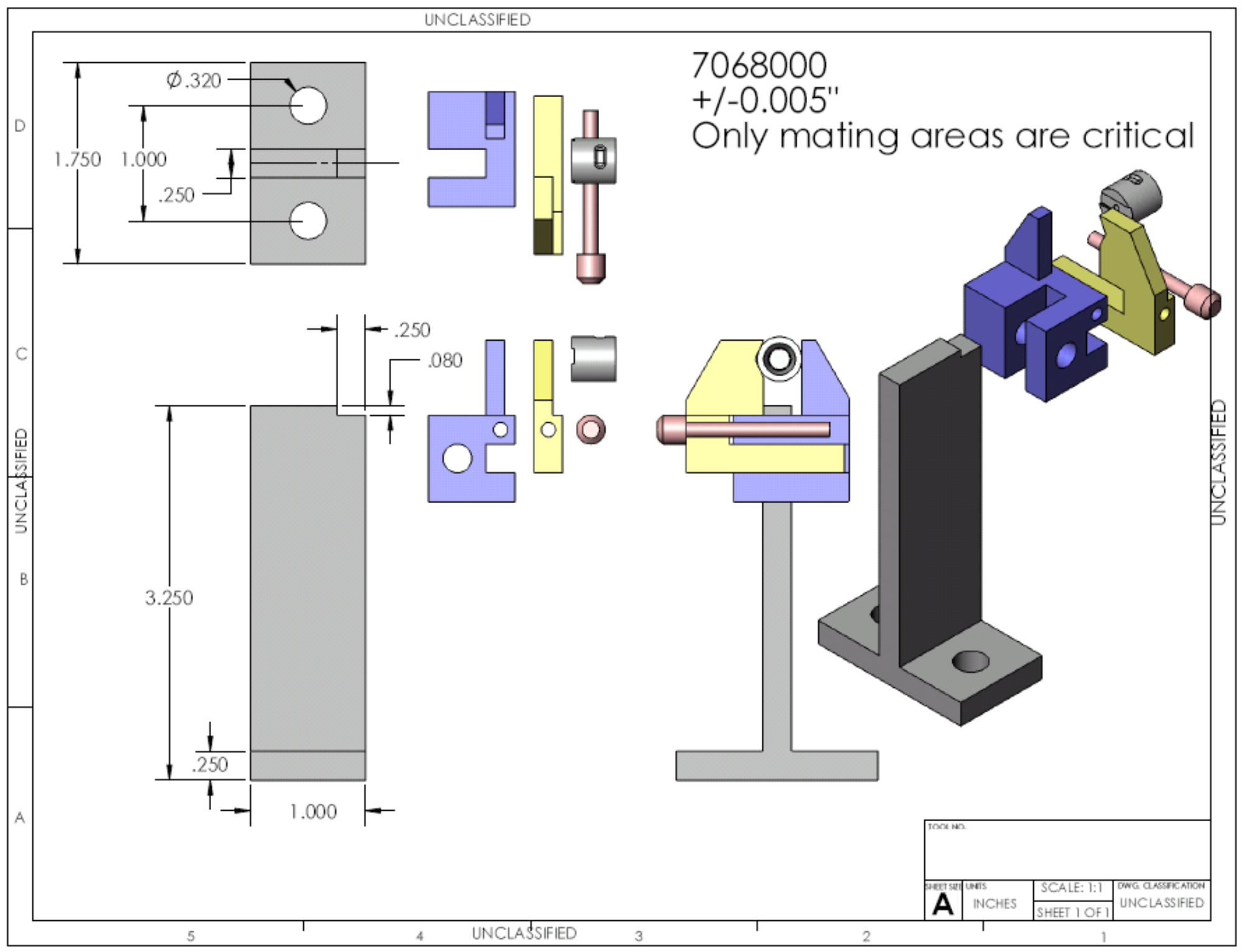




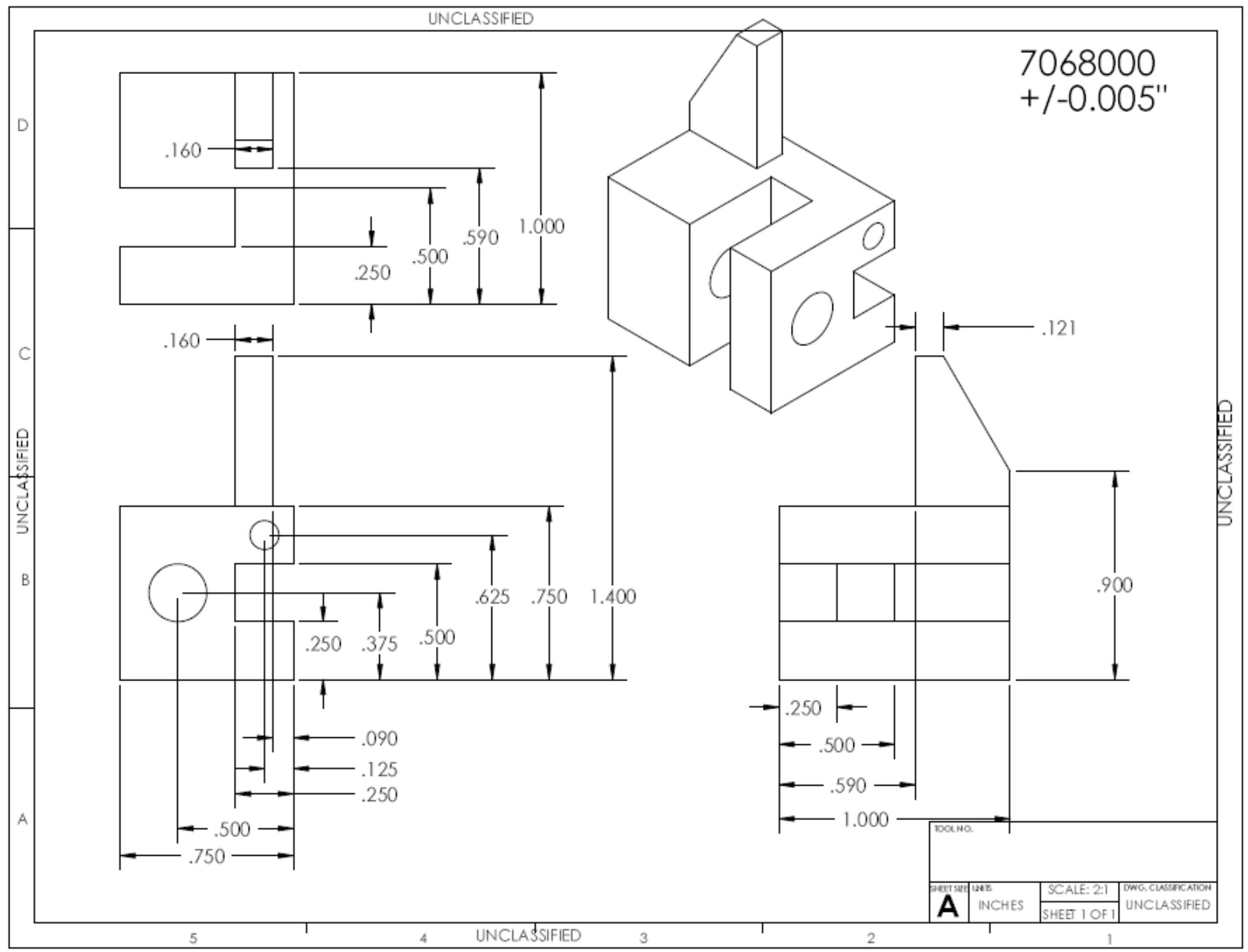




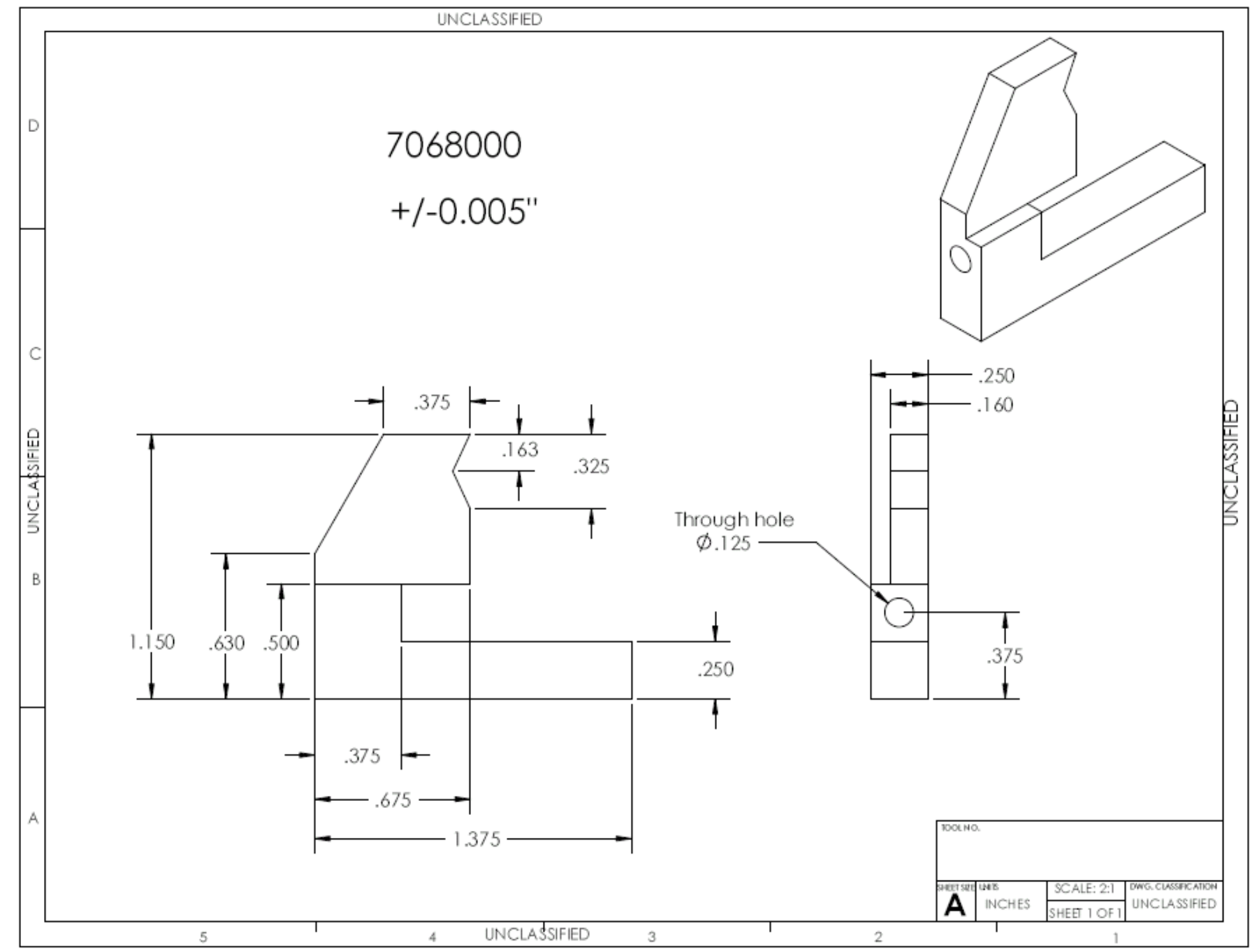




\section{Appendix B - Additional Project Information}

\section{Software and Hardware Info}

Silma XG V9.01 Shared license, 2 unclassified, 1 classified.

Metrolog XG V9.01 Dongle 7115 - D93

Dongle 7212 - Precision Measurement

CMM: $\quad$ Image 555,

Controller: Brown \& Sharp 


\section{Software Quality Assurance Documentation}

\section{SOFTWARE QUALITY ASSURANCE PLAN FOR IN-PROCESS CMM}

\section{Background}

This plan has been written to comply with the (SQA) requirements of Software Quality Assurance in Command Media. Software for this equipment meets the criteria found in Determine Software SQA category per Command Media (for Category 2 software). This SQA plan addresses the configuration management, verification, and validation of program files created by KCP personnel for the InProcess verification of production parts. The In-Process verification is operated via Metrolog XG software, programs stored on hard-drives, and manufacturing personnel manual inputs.

\section{Definitions}

System Software:

Executive software:
The operating software which integrates the PC and CMM controller. This CE\# system is Window base systems.

The CMM software which supplies the specific information required to verify in-process machined dimensions by controlling a motorized 3D touch trigger probe head to verify product. This program is created by KCP personnel. The file name (program name) of the appropriate software will be based on part number and operation ID of the production traveler.

Secondary software: $\quad$ DataPage is secondary software included in Software Maintenance Agreement (SMA) to be used to analyze CMM data.

\begin{tabular}{|c|c|c|}
\hline Machine Type & $\begin{array}{c}\text { Operating } \\
\text { System }\end{array}$ & $\begin{array}{c}\text { Executive } \\
\text { System }\end{array}$ \\
\hline Global Activ 555 & $\begin{array}{c}\text { Windows } \\
\text { XP Pro. }\end{array}$ & $\begin{array}{c}\text { Metrolog } \\
\text { XG }\end{array}$ \\
\hline
\end{tabular}

Full Control Mode:

Full access mode in which programmers use Metrolog XG to write, edit, and maintain programs 
Operator Mode:

Limited access mode in which machinists can operate the CMM system \& Metrolog XG to verify dimensions. Programs can not be altered or edited.

\section{Organization, Tasks, and Responsibilities}

The Process Engineer is responsible for writing the program that is used to verify inprocess product in Department A. Manufacturing personnel use the Metrolog XG software to verify their work in the Operator Mode. If a program has not been written, manufacturing personnel may request responsible personnel to provide a CMM program based on information supplied in the production traveler or specified drawing to run the job.

\section{Configuration Management}

The master copy of updated software is stored in the cabinet adjacent to the CMM. A ghost of the hard drive is located under the Test Equipment CMM Projects folder. Manufacturer provides software in CD.

The Process Engineer will ascertain the correct issue and incorporate it into the assigned folder to be used in Operator Mode.

A folder may have more than one working program in it, but must not contain two issues of the same program. The old program can be kept in separated folder from the master in the disk directory. CMM programs will be backed up on a defined period (once a month) into d93cmm directory.

\section{Software Verification and Validation}

Process Engineer may select the most stable version of Executive software to operate the CMM.

a. The Process Engineer will create or revise programs according to product requirements.

b. The CMM program will be validated by the Process Engineer that it marks the correct information.

c. Once validation is complete, the Process Engineer shall remove the old version from the working folder.

d. Management and validation of the system software is the responsibility of Equipment Maintenance Engineering department. 


\section{Software Documentation}

SMA is the system software documentation between the equipment manufacturer and the Kansas City Plant.

\section{Software Backups}

Program Backups, either on floppy disc or paper printout, shall exist for every current program on disk in excess of one Data Block or of suitable complexity to be saved. Backups shall be kept by the Engineering section responsible for writing the program. If backup copies of past issues or archived files are maintained, keep them labeled as "Outdated” or "History" and keep them unavailable to Manufacturing.

The system disk backup can be a physical backup or in the event of a manufacturer's copy protection, can consist of a printed computer code. System backups are stored by Equipment Maintenance Engineering or the Maintenance Crib responsible for the equipment. 